Research

\title{
Asn 362 in gp I 20 contributes to enhanced fusogenicity by CCR5-restricted HIV-I envelope glycoprotein variants from patients with AIDS
}

\author{
Jasminka Sterjovski1,2, Melissa J Churchill1,2, Anne Ellett ${ }^{1}$, Lachlan R Gray ${ }^{1,4}$, \\ Michael J Roche ${ }^{1}$, Rebecca L Dunfee ${ }^{5}$, Damian FJ Purcell ${ }^{4}$, Nitin Saksena ${ }^{6}$, \\ Bin Wang ${ }^{6}$, Secondo Sonza ${ }^{1,3}$, Steven L Wesselingh ${ }^{1,2,4}$, Ingrid Karlsson7 , Eva- \\ Maria Fenyo ${ }^{7}$, Dana Gabuzda ${ }^{5,8}$, Anthony L Cunningham ${ }^{6}$ and \\ Paul R Gorry*1,2,4
}

Address: ${ }^{1}$ Macfarlane Burnet Institute for Medical Research \& Public Health, Melbourne, Victoria, Australia, ${ }^{2}$ Department of Medicine, Monash University, Melbourne, Victoria, Australia, ${ }^{3}$ Department of Microbiology, Monash University, Melbourne, Victoria, Australia, ${ }^{4}$ Department of Microbiology and Immunology, University of Melbourne, Melbourne, Victoria, Australia, ${ }^{5}$ Dana-Farber Cancer Institute, Boston, MA, USA, ${ }^{6}$ Westmead Millennium Institute, Westmead, New South Wales, Australia, ${ }^{7}$ Lund University, Lund, Sweden and ${ }^{8}$ Department of Neurology, Harvard Medical School, Boston, MA, USA

Email: Jasminka Sterjovski - Jasminka@burnet.edu.au; Melissa J Churchill - Churchil@burnet.edu.au; Anne Ellett - amellett@burnet.edu.au; Lachlan R Gray - lachlang@burnet.edu.au; Michael J Roche - mroche@burnet.edu.au; Rebecca L Dunfee - dunfeer@niaid.nih.gov; Damian FJ Purcell -dfjp@unimelb.edu.au; Nitin Saksena - nitin_saksena@wmi.usyd.edu.au; Bin Wang - bin_wang@wmi.usyd.edu.au; Secondo Sonza - sonza@burnet.edu.au; Steven LWesselingh - stevew@burnet.edu.au; Ingrid Karlsson - ingrid.karlsson@cea.fr; EvaMaria Fenyo - eva_maria.fenyo@mmb.lu.se; Dana Gabuzda - dana_gabuzda@dfci.harvard.edu; Anthony LCunningham - tony_cunningham@wmi.usyd.edu.au; Paul R Gorry* - gorry@burnet.edu.au

* Corresponding author

\section{Published: 12 December 2007}

Retrovirology 2007, 4:89 doi:10.1186/1742-4690-4-89

This article is available from: http://www.retrovirology.com/content/4/I/89

(C) 2007 Sterjovski et al; licensee BioMed Central Ltd.

This is an Open Access article distributed under the terms of the Creative Commons Attribution License (http://creativecommons.org/licenses/by/2.0), which permits unrestricted use, distribution, and reproduction in any medium, provided the original work is properly cited.

\begin{abstract}
Background: CCR5-restricted (R5) human immunodeficiency virus type I (HIV-I) variants cause CD4+ T-cell loss in the majority of individuals who progress to AIDS, but mechanisms underlying the pathogenicity of R5 strains are poorly understood. To better understand envelope glycoprotein (Env) determinants contributing to pathogenicity of R5 viruses, we characterized 37 full-length R5 Envs from cross-sectional and longitudinal R5 viruses isolated from blood of patients with asymptomatic infection or AIDS, referred to as pre-AIDS (PA) and AIDS (A) R5 Envs, respectively.

Results: Compared to PA-R5 Envs, A-R5 Envs had enhanced fusogenicity in quantitative cell-cell fusion assays, and reduced sensitivity to inhibition by the fusion inhibitor T-20. Sequence analysis identified the presence of Asn 362 (N362), a potential N-linked glycosylation site immediately Nterminal to CD4-binding site (CD4bs) residues in the $C 3$ region of gp I20, more frequently in AR5 Envs than PA-R5 Envs. N362 was associated with enhanced fusogenicity, faster entry kinetics, and increased sensitivity of Env-pseudotyped reporter viruses to neutralization by the CD4bsdirected Env mAb IgGIbl2. Mutagenesis studies showed N362 contributes to enhanced fusogenicity of most A-R5 Envs. Molecular models indicate N362 is located adjacent to the CD4 binding loop of gp I20, and suggest N362 may enhance fusogenicity by promoting greater exposure of the CD4bs and/or stabilizing the CD4-bound Env structure.
\end{abstract}




\begin{abstract}
Conclusion: Enhanced fusogenicity is a phenotype of the A-R5 Envs studied, which was associated with the presence of N362, enhanced HIV-I entry kinetics and increased CD4bs exposure in gp 120. N362 contributes to fusogenicity of R5 Envs in a strain dependent manner. Our studies suggest enhanced fusogenicity of A-R5 Envs may contribute to CD4+ T-cell loss in subjects who progress to AIDS whilst harbouring R5 HIV-I variants. N362 may contribute to this effect in some individuals.
\end{abstract}

\section{Background}

The gp120 and gp41 envelope glycoprotein (Env) complexes of human immunodeficiency virus type 1 (HIV-1) mediate viral entry into cells (reviewed in [1-3]). The gp120 subunits bind to CD4 which induces conformational changes that lead to exposure of a binding site for a cellular coreceptor, either CCR5 or CXCR4. Coreceptor binding induces further conformational changes in gp41 that lead to fusion between the viral and cellular membranes and entry of the HIV-1 core into cells.

The coreceptor specificity of Env influences HIV-1 pathogenesis. Progression of HIV-1 infection from early, asymptomatic stages of disease to acquired immunodeficiency syndrome (AIDS) is associated with a switch in viral coreceptor specificity from CCR5-using (R5) viral strains to those able to use CXCR4 (X4) or both coreceptors (R5X4) in $40-50 \%$ of infected adults [4-8] (reviewed in [9]). However, X4 or R5X4 variants are absent in $50-60 \%$ of HIV-1 infected individuals who progress to AIDS [10-14] (reviewed in [15]). Therefore, the persistence of an exclusive R5 viral population in vivo is sufficient to cause immunodeficiency in the majority of HIV-1 infected individuals who progress to AIDS.

In addition to dictating HIV-1 coreceptor specificity, the Env glycoproteins cause significant cytotoxicity both in vitro and in vivo. Env mediates most of the acute cytopathic effects of HIV-1 infection in cultured cells [16], and membrane fusion appears to be an important factor contributing to HIV-1 cytopathicity in vitro [17]. Passage of chimeric simian-HIV (SHIV) strains in macaques demonstrated enhancement of pathogenicity that was associated with mutations in Env [18-23]. These Env mutations often resulted in increased Env-mediated membrane fusing capacity [20,23-26], suggesting that fusogenicity contributes to viral pathogenicity in this animal model. The cytopathic effects of Env-mediated HIV-1 fusogenicity are also evident in humans. For example, the presence of multinucleated giant cells (MNGC) in brain, formed by Env-mediated fusion between infected and uninfected macrophage lineage cells, is characteristic of HIV-1 encephalitis (HIVE) and a neuropathological hallmark of HIV-associated dementia (reviewed in [27]). Thus, Env-mediated fusogenicity appears to be an important factor contributing to HIV-1 pathogenesis.
Whilst much effort has been directed towards understanding the molecular basis of pathogenicity of late-emerging $\mathrm{X} 4$ and R5X4 viruses [28-30] (reviewed in [9]), the molecular mechanisms underlying the pathogenicity of R5 HIV1 strains are poorly understood [15]. R5 viruses are intrinsically cytopathic, but exert pathogenic effects that are distinct from those of X4 or R5X4 viruses [31-33]. R5 HIV-1 strains isolated from patients with AIDS (hereafter referred to as AIDS R5 (A-R5) viruses) have enhanced macrophage (M)-tropism [34-36] and cause increased levels of CD4+ T-cell death [37] compared with R5 HIV-1 strains isolated from asymptomatic individuals (hereafter referred to as pre-AIDS R5 (PA-R5) viruses). A-R5 viruses were shown to have increased in vivo cytopathicity in HIV1-infected SCID-hu mice compared with PA-R5 viruses in one study [38], although different conclusions were reached by other in vivo and ex vivo studies $[39,40]$. A-R5 viruses have decreased sensitivity to inhibition by the $\beta$ chemokine RANTES (Regulated on Activation, Normally T-cell-expressed and -secreted) compared with PA-R5 viruses $[10,13,14]$. Recent evidence suggests that decreased RANTES sensitivity is attributed to an increased flexibility of the R5 Env that alters the mode and efficiency of CCR5 usage [13]. In addition, A-R5 viruses have decreased sensitivity to inhibition by the HIV-1 fusion inhibitor T-20 and by the CCR5 antagonist TAK-779 compared with PA-R5 viruses $[36,41]$, but have increased sensitivity to neutralization by the CD4 binding site (CD4bs) directed Env monoclonal antibody (mAb) IgG1b12 [36]. Together, these findings provide evidence that A-R5 viruses have intrinsic properties distinguishing them from PA-R5 viruses which may enhance their cytopathic effects, and that these properties are likely to be linked to Env conformations that enhance CD4 and/or CCR5 interactions.

Genetic determinants of the Env underlying these A-R5 HIV-1 phenotypes, which may contribute to HIV-1 pathogenesis in subjects who persistently harbor R5 HIV-1 variants to late stages of HIV-1 infection are unknown. To better understand Env determinants contributing to pathogenicity of R5 viruses, we characterized R5 Envs generated from cross-sectional and longitudinal panels of PAR5 and A-R5 viruses. Our results show that enhanced fusogenicity is a phenotype of A-R5 Envs. We identified the presence of Asn 362 (N362), a potential N-linked gly- 
cosylation site immediately $\mathrm{N}$-terminal to $\mathrm{CD} 4 \mathrm{bs}$ residues in the C3 region of gp120, more frequently in A-R5 Envs than PA-R5 Envs. N362 was associated with enhanced fusogenicity, reduced sensitivity to the inhibitory effects of T-20, faster entry kinetics, and increased sensitivity of Env-pseudotyped reporter viruses to neutralization by the CD4bs-directed Env mAb IgG1b12. Mutagenesis studies showed that N362 contributes to fusogenicity of R5 Envs in a strain dependent manner. Structural models indicate that N362 is located adjacent to the CD4 binding loop of gp120, and suggest N362 may contribute to enhanced fusogenicity by promoting greater exposure of the CD4bs and/or stabilizing the CD4-bound Env structure. This prediction is consistent with the increased sensitivity of A-R5 Envs with N362 to neutralization by IgG1b12. Enhanced fusogenicity of A-R5 Envs may contribute, at least in part, to CD4+ T-cell loss in subjects who progress to AIDS whilst harbouring R5 HIV-1 variants.

\section{Results}

\section{Primary PA-R5 and A-R5 HIV-I isolates}

We characterized HIV-1 Envs cloned from a series of well characterized primary PA-R5 and A-R5 viruses. These included a cross sectional panel of four PA-R5 viruses (NB23, NB24, NB25 and NB27) and four A-R5 HIV-1 viruses (NB2, NB6, NB7 and NB8) [34,36], as well as PA$\mathrm{R} 5$ and A-R5 viruses isolated sequentially from one subject (IK1) [13,42] (Table 1). All viruses are of R5 phenotype, but compared to the PA-R5 viruses the A-R5 viruses have enhanced M-tropism, reduced CD4- and CCR5dependence, reduced sensitivity to inhibition by HIV-1 entry inhibitors and RANTES, and increased sensitivity to neutralization by the Env mAb IgG1b12 [13,34,36,42]. Thus, the A-R5 HIV-1 isolates have unique biological properties distinguishing them from the PA-R5 isolates that serve to enhance Env-receptor interactions, and most likely map to the env gene. However, it is important to note that the PA-R5 virus from subject IK1 was isolated just prior to the onset of CD4+ T-cell loss and progression toward AIDS [13], whereas the PA-R5 viruses from the cross sectional panel were isolated at earlier stages of HIV1 infection, including one virus isolated from an acute seroconverter [34]. Therefore, although all the A-R5 viruses were isolated from patients with AIDS, there is considerable heterogeneity among the PA-R5 viruses with respect to the stage of asymptomatic HIV-1 infection from which they were isolated.

\section{Biological activities of HIV-I Env clones}

To identify viral determinants which underlie the unique biological properties of A-R5 HIV-1 viruses and may contribute to the pathogenesis of R5 HIV-1 variants, the env gene was cloned into the PSVIII-HXB2 Env expression vector using KpnI and BamHI restriction sites. Three to four independent and functional Envs cloned from each virus were identified by single round entry assays in JC53 or Cf2-CD4/CCR5/CXCR4 cells using Env-pseudotyped GFP reporter virus, and by fusion assays (Table 1 , and data not shown). Western blot analysis of Env expression in transfected 293T cells showed distinct gp160 and gp120 proteins in 36/37 primary Envs, similar to the control R5 ADA, YU2, JRFL and JRCSF Envs (Fig. 1). To determine the coreceptor specificity of the cloned Envs, Env-pseudotyped GFP reporter viruses were used in single round entry assays with Cf2th cell lines stably expressing CD4/CCR5 or CD4/CXCR4 (Table 1). The X4 HXB2, R5 ADA, and R5X4 89.6 Envs were used as positive controls. A non functional Env, $\Delta K S$ Env, was used as a negative control to determine background levels of GFP expression. As expected, HXB2 Env used CXCR4, ADA Env used CCR5, and 89.6 Env used both CXCR4 and CCR5 for HIV-1 entry. All 37 primary Envs used CCR5 for HIV-1 entry, similar to the coreceptor specificity of the primary isolates from which they were cloned. Thus, we established and validated a bank of functional PA-R5 and A-R5 Envs cloned from well characterized primary R5 HIV-1 isolates.

\section{A-R5 Envs have enhanced fusogenicity compared to PA-R5 Envs}

Alterations in Env that augment fusogenicity contribute to the pathogenesis of SHIV infection [20,23-26]. In addition, HIV-1 fusogenicity is evident as MNGCs in tissues such as brain, which frequently harbors highly fusogenic R5 HIV-1 strains that share a number of phenotypic characteristics with blood-derived A-R5 viruses [43-46]. We used a quantitative cell-cell fusion assay to determine whether A-R5 Envs are more fusogenic than PA-R5 Envs. In this assay, cells were sampled at 2-hourly intervals until maximal fusion levels were reached at 12 hours post-mixing of Env-expressing effector cells and CD4/CCR5expressing target cells. A-R5 Envs from the cross-sectional panel caused greater levels of cell-cell fusion than the PAR5 Envs, which was particularly evident at 10 and $12 \mathrm{~h}$ post-mixing (Fig. 2A). The differences in fusogenicity between PA- and A-R5 Envs were not due to differences in cell surface Env expression levels on effector cells (Fig. 2B). When maximal fusion levels attained by PA- and AR5 Envs were stratified across very low $(+/-)$, low $(+)$, moderate $(++)$ or high (+++) maximal levels, the majority of A-R5 Envs had either moderate or high maximal fusion levels, whereas the majority of PA-R5 Envs had either very low or low maximal fusion levels (Fig. 2C). Thus, the AR5 Envs from the cross-sectional panel are more fusogenic than the PA-R5 Envs.

We next tested whether A-R5 Envs from IK1 are more fusogenic than PA-R5 Envs cloned from this subject. A-R5 Envs from IK1 caused greater levels of cell-cell fusion than matched PA-R5 Envs, which was evident at 8, 10 and $12 \mathrm{~h}$ post-mixing (Fig. 3A). The differences in fusogenicity 
Table I: Characteristics of primary R5 viruses and Env clones

\begin{tabular}{|c|c|c|c|c|}
\hline \multirow[t]{2}{*}{ Virus $^{\mathrm{a}}$} & \multirow[t]{2}{*}{ Description $^{b}$} & \multirow[t]{2}{*}{ Env clone ${ }^{c}$} & \multicolumn{2}{|c|}{ Coreceptor usage $^{d}$} \\
\hline & & & CCR5 & CXCR4 \\
\hline Cross-sectional viruses & & & & - \\
\hline \multirow[t]{3}{*}{ NB23 } & PA-R5 & $\mathrm{NB} 23-\mathrm{Cl}$ & +++ & - \\
\hline & & NB23-C2 & +++ & - \\
\hline & & NB23-C3 & +++ & - \\
\hline \multirow[t]{4}{*}{ NB24 } & PA-R5 & NB24-CI & ++ & - \\
\hline & & NB24-C2 & + & - \\
\hline & & NB24-C3 & + & - \\
\hline & & NB24-C4 & + & - \\
\hline \multirow[t]{3}{*}{ NB25 } & PA-R5 & NB25-CI & + & - \\
\hline & & NB25-C2 & + & - \\
\hline & & NB25-C3 & +++ & - \\
\hline \multirow[t]{3}{*}{ NB27 } & PA-R5 & NB27-CI & + & - \\
\hline & & NB27-C2 & ++ & - \\
\hline & & NB27-C3 & +++ & - \\
\hline \multirow[t]{4}{*}{ NB2 } & A-R5 & NB2-Cl & + & - \\
\hline & & NB2-C2 & + & - \\
\hline & & NB2-C3 & ++ & - \\
\hline & & NB2-C4 & ++ & - \\
\hline \multirow[t]{4}{*}{ NB6 } & A-R5 & NB6-Cl & +++ & - \\
\hline & & NB6-C2 & +++ & - \\
\hline & & NB6-C3 & +++ & - \\
\hline & & NB6-C4 & +++ & - \\
\hline \multirow[t]{4}{*}{ NB7 } & A-R5 & NB7-CI & ++ & - \\
\hline & & NB7-C2 & ++ & - \\
\hline & & NB7-C3 & ++ & - \\
\hline & & NB7-C4 & ++ & - \\
\hline \multirow[t]{4}{*}{ NB8 } & A-R5 & NB8-CI & +++ & - \\
\hline & & NB8-C2 & +++ & - \\
\hline & & NB8-C3 & +++ & - \\
\hline & & NB8-C4 & +++ & - \\
\hline \multicolumn{5}{|l|}{ Longitudinal viruses } \\
\hline \multirow[t]{4}{*}{ IKI-PA } & PA-R5 & IKI-PA-CI & ++ & - \\
\hline & & IKI-PA-C2 & + & - \\
\hline & & IKI-PA-C3 & ++ & - \\
\hline & & IKI-PA-C4 & + & - \\
\hline \multirow[t]{4}{*}{ IKI-A } & A-R5 & $\mid \mathrm{KI}-\mathrm{A}-\mathrm{Cl}$ & ++ & - \\
\hline & & IKI-A-C2 & +++ & - \\
\hline & & IKI-A-C3 & ++ & - \\
\hline & & IKI-A-C4 & ++ & - \\
\hline \multicolumn{5}{|l|}{ Controls } \\
\hline & & $\Delta K S$ Env & - & - \\
\hline & & HXB2 Env & - & +++ \\
\hline & & ADA Env & +++ & - \\
\hline & & 89.6 Env & +++ & +++ \\
\hline
\end{tabular}

aThe phenotypes of the primary R5 HIV-I isolates, and clinical characteristics of the subjects from whom they were isolated have been described in detail previously [II, I3, 34, 36, 42].

bPA-R5, pre-AIDS R5 HIV-I isolate; A-R5, AIDS R5 HIV-I isolate.

cFunctional Env clones were identified by infection of JC53 cells or Cf2-CD4/CCR5/CXCR4 cells with Env-pseudotyped GFP reporter viruses and by fusion assays, as described in the Methods (data not shown).

dCoreceptor usage of functional Envs was determined by infection of Cf2-CD4/CCR5 and Cf2-CD4/CXCR4 cell lines with Env-pseudotyped GFPreporter viruses, as described in the Methods. GFP positive cells were counted manually by fluorescence microscopy and scored as - (no GFP positive cells), +/- (I to $5 \%$ GFP positive cells), + (5 to I0\% GFP positive cells), ++ (10 to 30\% GFP positive cells), or +++ (>30\% GFP positive cells). 


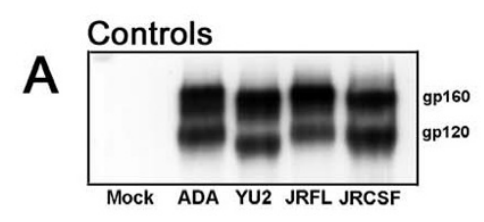

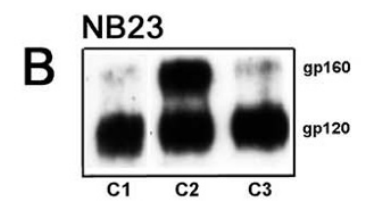
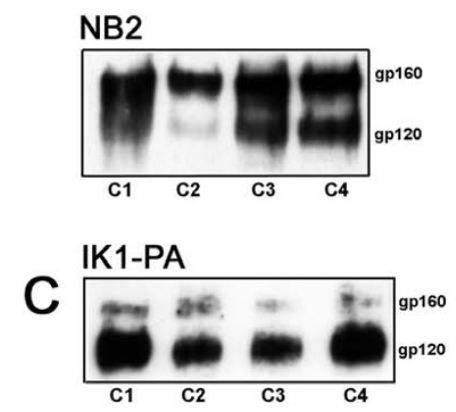
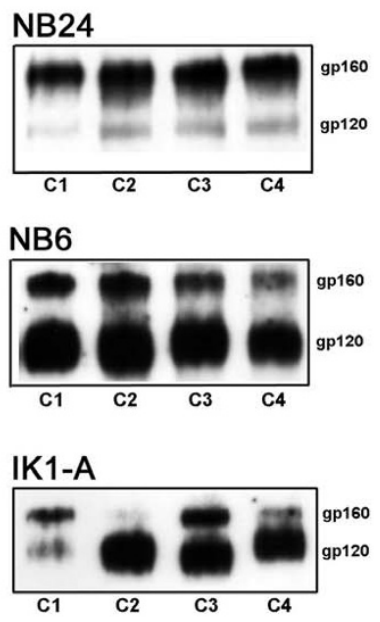

NB25

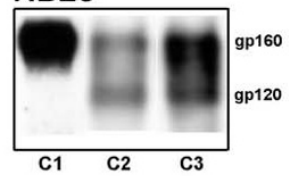

NB7

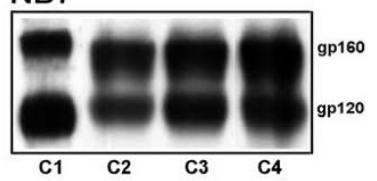

NB27

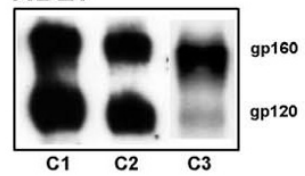

NB8

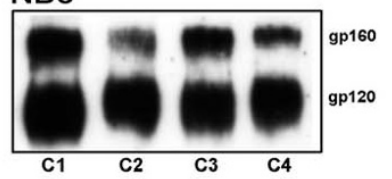

Figure I

Expression of functional Env clones. 293T cells were cotransfected with $8 \mu \mathrm{g}$ of pSVIII-Env plasmid expressing control R5 Envs (A) or PSVIII-Env plasmid expressing functional Envs cloned from the cross sectional (PA-R5 viruses NB23, NB24, NB25, NB27 and A-R5 viruses NB2, NB6, NB7, NB8) (B) or longitudinal (PA- and A-R5 viruses from subject IKI) (C) primary R5 HIV-I isolates and $2 \mu \mathrm{g} \mathrm{PSVL-Tat,} \mathrm{as} \mathrm{described} \mathrm{in} \mathrm{the} \mathrm{Methods.} \mathrm{Env} \mathrm{expression} \mathrm{at} 72 \mathrm{~h}$ post-transfection was measured by Western blot analysis of cell lysates using rabbit anti-gp I 20 polyclonal antisera. Positions of gp I60 and gp I 20 are shown on the right. $\mathrm{Cl}, \mathrm{C} 2, \mathrm{C} 3$ and $\mathrm{C} 4$ refer to independent Envs cloned from each virus.

between the PA-R5 and A-R5 Envs were not due to differences in cell surface Env expression levels on effector cells (Fig. 3B). In fact, in these experiments PA-R5 Envs were expressed to greater levels on effector cells than A-R5 Envs. The extent of cell-cell fusion is directly related to the level of Env expression on effector cells (J. Sterjovski and P.R. Gorry, unpublished data). Thus, in subject IK1, A-R5 Envs are more fusogenic than PA-R5 Envs, and the differences shown in Figure 3A are likely to be conservative.

\section{A-R5 Envs are less sensitive to inhibition by the HIV-I fusion inhibitor T-20 than PA-R5 Envs}

Enhanced fusogenicity of A-R5 Envs suggests that these Envs may be less sensitive to the antiviral effects of the HIV-1 fusion inhibitor T-20 than PA-R5 Envs. Therefore, we next determined the sensitivity of A-R5 and PA-R5 Envs from the cross sectional viruses to inhibition by $\mathrm{T}$ 20. Quantitative cell-cell fusion assays were carried out in the presence of 10 -fold increasing concentrations of T-20 ranging from 0.001 to $10 \mu \mathrm{g}$ per $\mathrm{ml}$, and $\mathrm{IC}_{50}$ and $\mathrm{IC}_{80}$ values calculated by regression analysis of inhibition curves. The results demonstrate a significant increase in the $\mathrm{IC}_{50}$ (Fig. 4A) and a non-significant trend toward an increase in the $\mathrm{IC}_{80}$ (Fig. 4B) for T-20 against A-R5 Envs compared to PA-R5 Envs. These differences were not due to differences in cell surface Env expression levels on effector cells (Fig. 4C). Thus, highly fusogenic A-R5 Envs appear to be less sensitive to the inhibitory effects of T-20 in cell-cell fusion assays compared to less fusogenic PA-R5 Envs.

\section{N362 adjacent to CD4bs residues in gp I 20 is conserved in A-R5 but not PA-R5 Envs}

To identify amino acid variants associated with A-R5 Envs that may contribute to enhanced fusogenicity, the gp120 region of the 37 Envs was sequenced and analyzed. Phylogenetic analysis of Envs demonstrated tight clustering of nucleotide sequences according to virus isolate (data not shown). Multiple sequence alignments verified that all sequences were unique (data not shown). Together, these data demonstrate that the Envs are independent clones and not the result of sequence resampling.

A-R5 and PA-R5 Envs could not be segregated based on the total number of potential N-linked glycosylation sites (PNGS) in gp120 (range, 16 to 24 PNGS; median 19), length of the V1V2 variable loops (range, 68 to 83 amino 

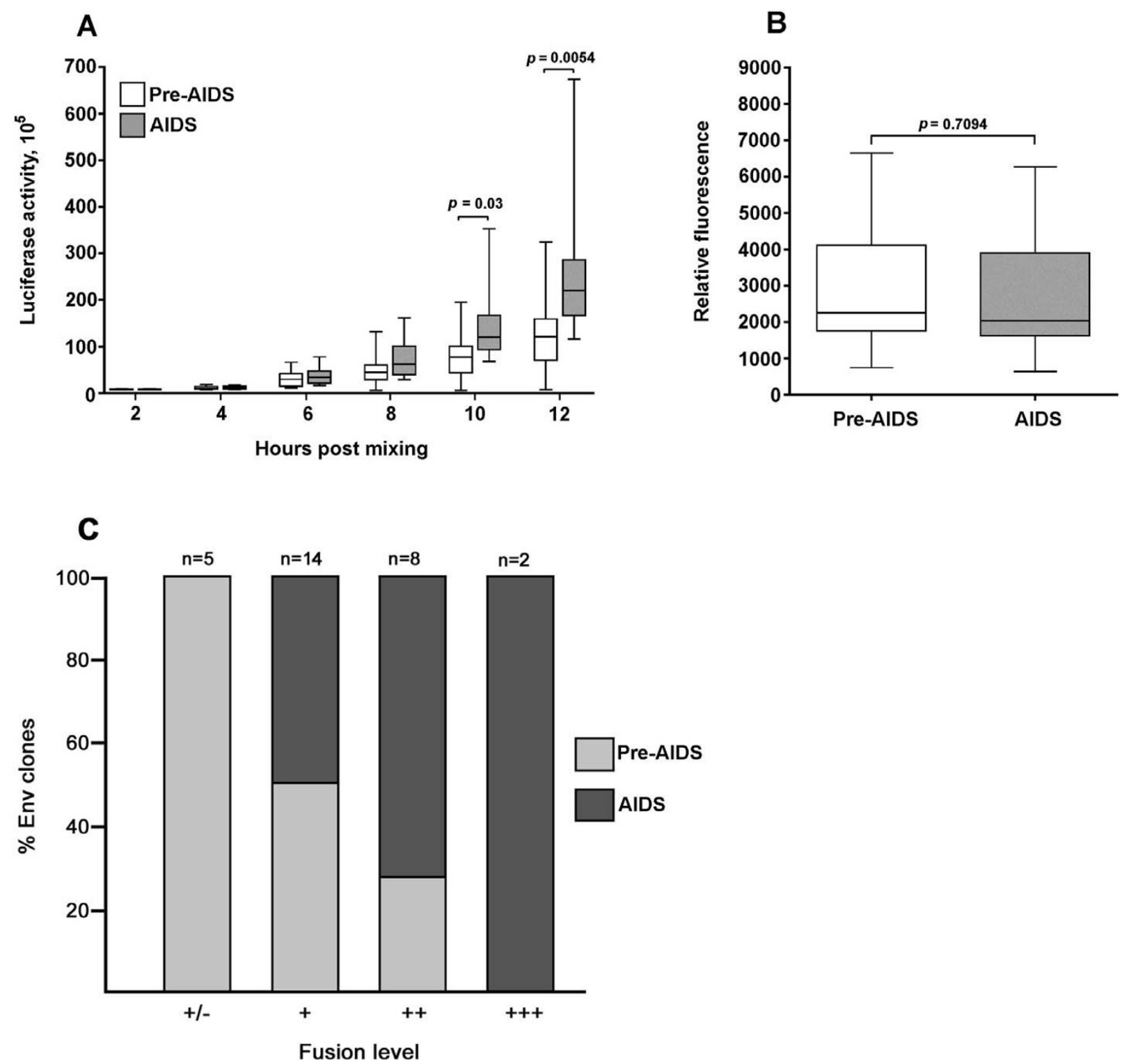

Figure 2

Fusogenicity of PA-R5 and A-R5 Envs cloned from the cross-sectional panel of primary R5 HIV-I isolates. Fusion assays were performed using 293T effector cells expressing PA-R5 and A-R5 Envs shown in Fig. IB and Cf2-Luc target cells expressing CD4 and CCR5, as described in the Methods. Cells were harvested at 2, 4, 6, 8, 10 and $12 \mathrm{~h}$ post-mixing and assayed for luciferase activity (A). 293T effector cells were stained for cell surface Env expression using pooled AIDS serum and analysed by flow cytometry, as described in the Methods (B). The data were stratified by different maximal levels of fusion scored as $+/-,+,++$, and +++ , which correspond to <10-fold (very low), 10- to 20-fold (low), 20- to 40-fold (moderate), and $>40$-fold (high) increases in luciferase activity above background levels, respectively (C). Box plots were constructed from mean values of duplicate experiments with each Env using Prism version 4.0c (GraphPad Software, San Diego, CA.). Boxes represent upper and lower quartiles and median scores, and whiskers represent minimum and maximum values. The data shown are representative of 3 independent experiments. $P$ values were calculated using a nonparametric Mann-Whitney $U$ test, and values $<0.05$ were considered statistically significant. 

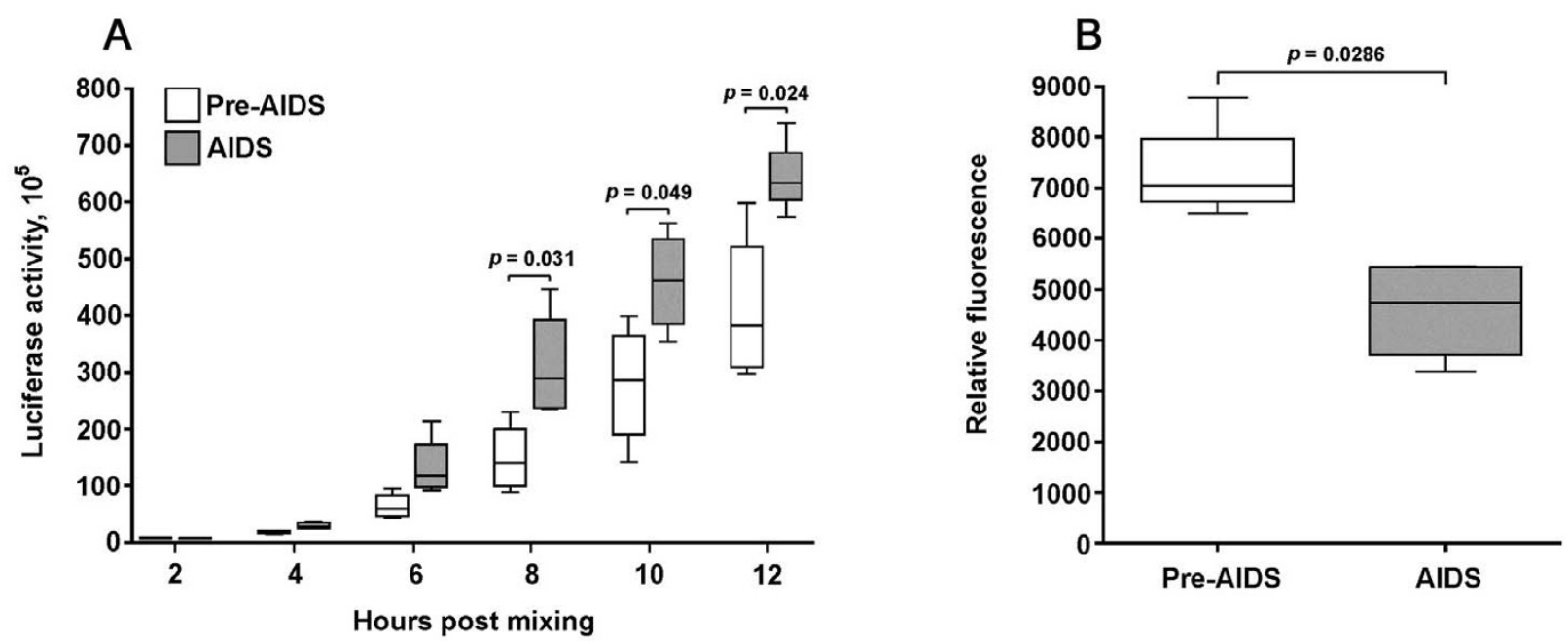

Figure 3

Fusogenicity of PA-R5 and A-R5 Envs cloned from longitudinal primary R5 HIV-I isolates. Fusion assays were performed using 293T effector cells expressing PA-R5 and A-R5 Envs cloned from longitudinal viruses isolated from subject IKI shown in Fig. IC, and Cf2-Luc target cells expressing CD4 and CCR5 as described in the Methods. Cells were harvested at 2 , $4,6,8,10$ and $12 \mathrm{~h}$ post-mixing and assayed for luciferase activity (A). 293T effector cells expressing Envs were stained for cell surface Env expression using pooled AIDS serum and analysed by flow cytometry, as described in the Methods (B). Box plots were constructed from mean values of duplicate experiments with each Env using Prism version 4.0c (GraphPad Software). Boxes represent upper and lower quartiles and median scores, and whiskers represent minimum and maximum values. The data shown are representative of 3 independent experiments. $P$ values were calculated using a nonparametric Mann-Whitney $U$ test, and values $<0.05$ were considered statistically significant.

A

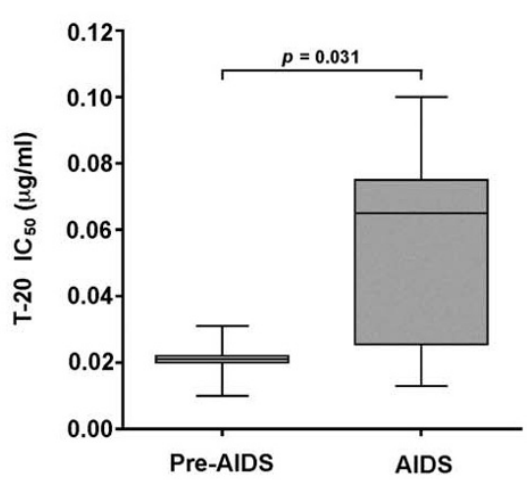

B

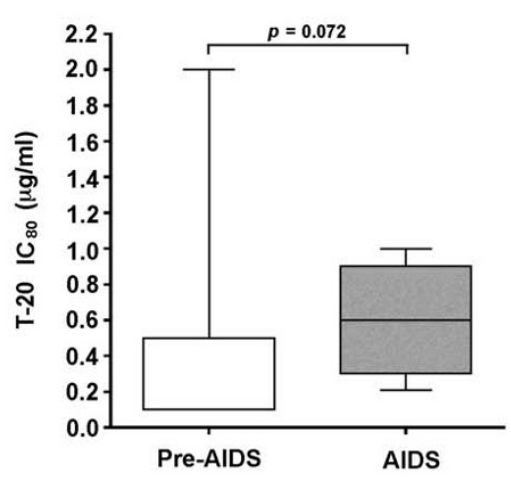

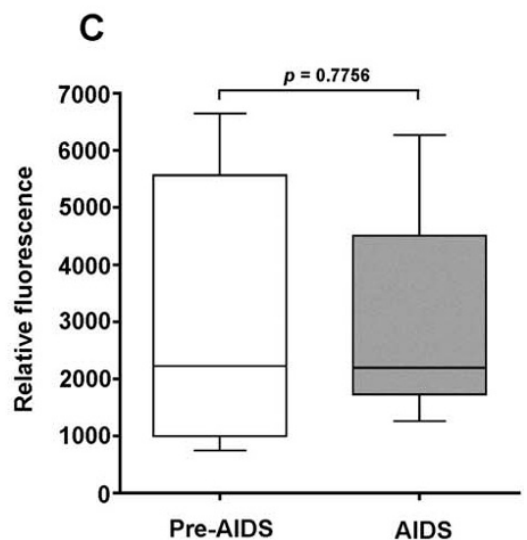

Figure 4

Sensitivity of PA-R5 and A-R5 Envs to inhibition by T-20. Fusion assays were performed using 293T effector cells expressing PA-R5 and A-R5 Envs from the cross sectional panel of primary R5 HIV-I isolates shown in Fig. IA, and Cf2-Luc target cells expressing CD4 and CCR5 in the presence of 10 -fold increasing concentrations of T-20 ranging from $0.00 \mathrm{I}$ to 10 $\mu \mathrm{g}$ per $\mathrm{ml}$, as described in the Methods. $\mathrm{IC}_{50}(\mathrm{~A})$ and $\mathrm{IC}_{80}(\mathrm{~B})$ values were calculated by least squares analysis of inhibition curves. $I C_{80}$ values were calculated instead of $I C_{90}$ values, because $90 \%$ inhibition of fusion was not reached when these concentrations of T-20 were tested against some of the A-R5 Envs (data not shown). 293T effector cells were stained for cell surface Env expression using pooled AIDS serum and analysed by flow cytometry, as described in the Methods (C). Box plots were constructed from mean values of duplicate experiments with each Env using Prism version 4.0c (GraphPad Software). Boxes represent upper and lower quartiles and median scores, and whiskers represent minimum and maximum values. The data shown are representative of 3 independent experiments. $P$ values were calculated using a nonparametric Mann-Whitney $U$ test, and values $<0.05$ were considered statistically significant. 
acids; median 72), net charge of the V1V2 (range, -3 to +4 ; median +1 ) or V3 (range, +3 to +8 , median +5 ) amino acid sequence, or number of PNGS in the V4 (range, 3 to 6 PNGS, median 4 ) or V5 (range 0 to 2 PNGS, median 1) sequence (data not shown), which are parameters shown previously to affect the biological activity of HIV-1 Envs [47-55]. Net charge of the V3 variable loop region did not predict coreceptor usage, consistent with results of previous studies $[44,46,56,57]$.

Signature pattern analysis of A-R5 and PA-R5 Envs from the cross-sectional viruses identified an amino acid variant, N362, that was present more frequently in A-R5 Envs (14/15 Envs; 93\%) than PA-R5 Envs (6/13 Envs; 46\%) (Fig. 5). No additional Env changes that could potentially distinguish A-R5 Envs from PA-R5 Envs were identified. Consistent with these results, database analysis of published Env sequences where sufficient clinical information was present to confidently assign Envs as A-R5 or PA-R5 [34,38,58-65] demonstrated N362 is significantly more frequent in A-R5 Envs (74\%; $\mathrm{n}=142)$ compared with PAR5 Envs (49\%; $n=77)(p=0.0004$, Fisher's exact test). N362 is located in the C3 Env region immediately N-terminal to residues in the CD4bs [50], suggesting that N362 could potentially influence Env-CD4 binding. N362 is also present in ADA and YU2 R5 Envs, which are highly fusogenic, similar to the majority of A-R5 Envs (data not shown). In contrast, threonine is present at this position in JR-CSF Env, which is poorly fusogenic, similar to the majority of PA-R5 Envs (data not shown). Thus, the presence of N362 is associated with A-R5 Envs from the crosssectional panel and other published Env sequences, and may contribute to enhanced fusogenicity. However, since N362 is present in a relatively high proportion of PA-R5 Envs from the cross sectional viruses (6/13) and other published studies (49\%), any effect N362 may have on the biological activity of A-R5 Envs is likely to be strainspecific and/or context dependent.

\section{N362 is associated with enhanced fusogenicity and reduced sensitivity to inhibition by $T-20$}

The preceding studies showed a predominance of A-R5 Envs containing N362, but Envs from two PA-R5 viruses, NB23 and NB27, also contained N362. Furthermore, although the fusogenicity of A-R5 Envs from the cross-sectional panel was significantly greater than that of the PAR5 Envs, there was still considerable overlap. To better understand the relationship between the presence of N362, fusogenicity, and sensitivity to T-20, these data were stratified based on the presence or absence of N362 (Fig. 6). R5 Envs containing N362 had significantly greater maximal levels of cell-cell fusion than R5 Envs lacking N362 (Fig. 6A). The differences in cell-cell fusion between Envs containing or lacking N362 were not due to differences in cell surface Env expression levels on effector cells (Fig. 6B). Envs containing N362 had a significantly higher $\mathrm{IC}_{80}$ and a trend toward a higher $\mathrm{IC}_{50}$ for T-20 than Envs lacking N362 (Fig. 6C,D). Together, these data demonstrate an association between the presence of N362 in R5 Envs from the cross sectional panel and enhanced fusogenicity, and an additional association between the presence of N362 and sensitivity to the inhibitory effects of T-20 in cell-cell fusion assays.

\section{Molecular modeling of N362}

Previous studies of brain-derived Envs identified the N283 variant in the $\mathrm{C} 2$ region of gp120 within one of the CD4 contact sites, which increases Env-CD4 affinity and enhances M-tropism [43]. Since blood-derived A-R5 viruses have enhanced M-tropism compared to PA-R5 viruses [34,36], and N362 is located immediately N-terminal to another $\mathrm{CD} 4$ contact site in the $\mathrm{C} 3 \mathrm{gp} 120$ region [Fig. 5 and [50]], we hypothesized that N362 may potentially affect Env structure and CD4 binding. N362, a potential site for $\mathrm{N}$-linked glycosylation, was modelled on the unliganded crystal structure of SIV gp120 and CD4liganded crystal structure of HIV-1 JRFL gp120. The CD4bs in the unliganded gp120 is located in the outer domain and consists of a disordered loop flanked by the $\beta-14$ and $\beta-16$ strands. N362 is positioned just distal to the $\beta-14$ strand in the disordered loop region of the CD4 binding motif (Fig. 7A). Upon binding to CD4, conformational changes lead to interactions between the $\beta-14, \beta-18$ and $\beta-24$ strands to form an antiparallel sheet (Fig. 7B), which is one of two major conformational changes that occur in gp120 upon CD4 binding [66]. Analysis of interatomic contacts within the antiparallel sheet region showed that N362 has the potential to form hydrogen bonds with one or more residues from within the $\beta-14$ strand and/or neighbouring strands of the $\beta$-sheet, including V360, F361, H363, F468, and R469 (Fig. 7C). Modeling glycosylated residues on the CD4-bound gp120 demonstrated N362 is in close proximity to N392, another potentially glycosylated residue in the $\beta-18$ strand (data not shown). Thus, N362 may be important in formation of the CD4-bound structure of gp120, and may contribute to the stability of the CD4-bound conformation of gp 120 by forming intramolecular hydrogen bonds with residues from neighbouring strands and/or interaction with other glycosylated residues.

\section{A-R5 Envs with N362 have faster entry kinetics than PA-R5 Envs lacking N362}

The structural models suggest N362 may influence CD4 binding and thus, the efficiency of HIV-1 entry. To better understand how N362 may enhance the entry of A-R5 Envs, we produced single-round luciferase reporter viruses pseudotyped with a subset of A-R5 Envs containing N362 (NB6-C2, NB6-C3, NB6-C4, NB7-C2, NB7-C4, NB8-C2 and NB8-C4) or with a subset of PA-R5 Envs lacking N362 


\section{Asn 362 CD4bs}

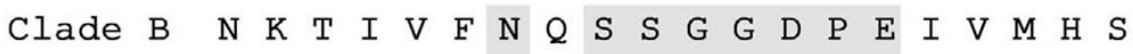

\section{Control R5 Envs}

YU2

ADA

JR-CSF

\section{PA-R5 Envs}

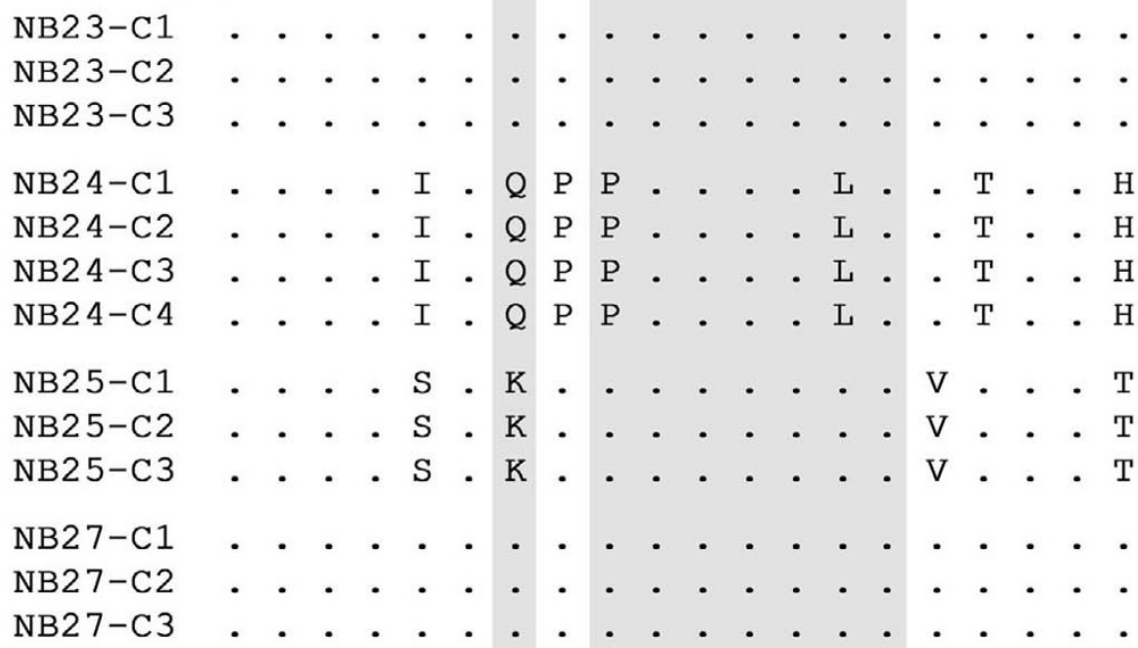

\section{A-R5 Envs}

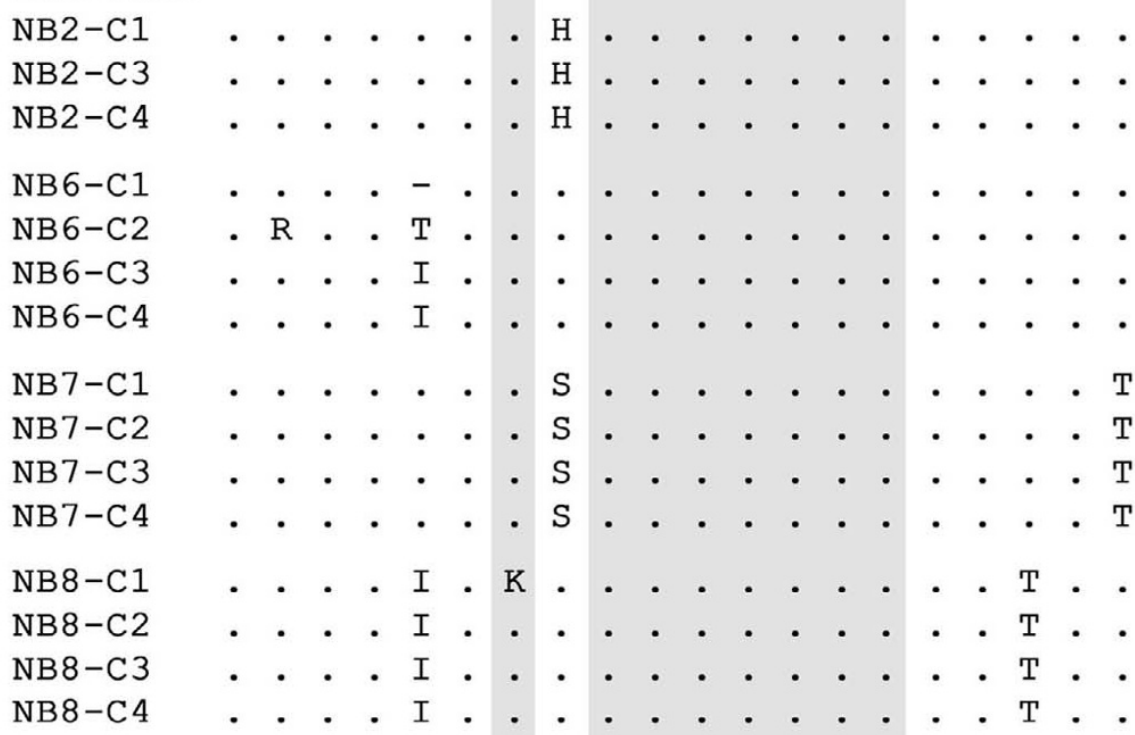

\section{Figure 5}

Amino acid sequences spanning the CD4bs in the C3 region of gp I 20. Amino acid alignments of the C3 region of PAR5 and A-R5 Envs cloned from the cross sectional panel of primary HIV-I isolates are compared to those from the highly fusogenic YU2 and ADA R5 Envs, the poorly fusogenic JR-CSF R5 Env, and the clade B consensus sequence. Dots indicate residues identical to the clade $B$ consensus sequence, and dashes indicate gaps. Residues forming the CD4bs and the amino acid present at position 362 (numbered relative to the HXB2 reference sequence) are highlighted. 

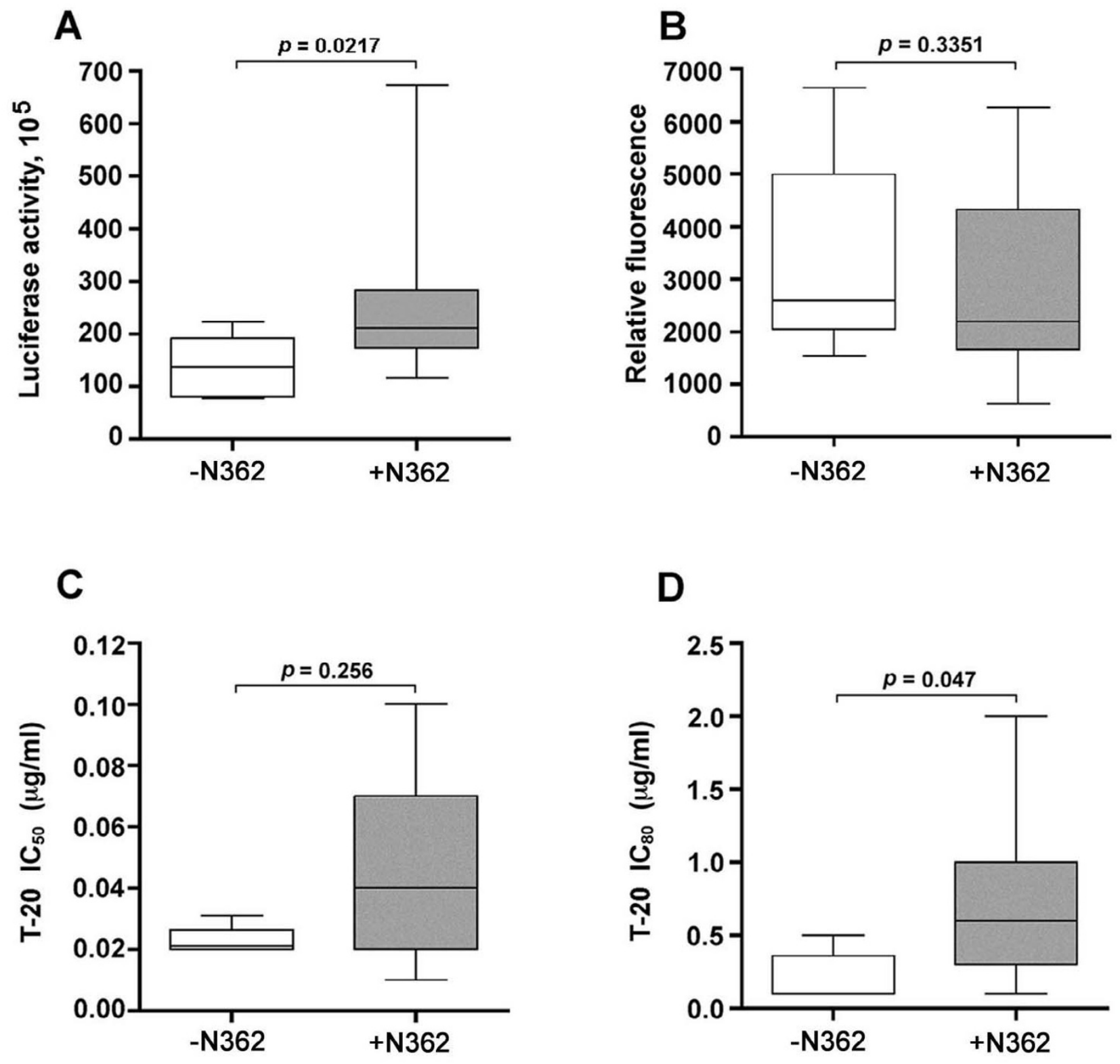

\section{Figure 6}

N362 is associated with enhanced fusogenicity and reduced sensitivity to T-20. For each of the Envs cloned from the cross sectional panel of primary R5 HIV-I viruses, the maximal levels of fusion (determined at $12 \mathrm{~h}$ post-fusion) (A), cell surface Env expression on 293T effector cells $(B)$, and $I C_{50}(C)$ and $I C_{80}(D)$ values for sensitivity to inhibition by T-20, were stratified based on the presence or absence of N362. Box plots were constructed from mean values of duplicate experiments with each Env using Prism version 4.0c (GraphPad Software). Boxes represent upper and lower quartiles and median scores, and whiskers represent minimum and maximum values. The data shown are representative of 3 independent experiments.

(NB24-C1, NB24-C2, NB24-C3, NB24-C4, NB25-C2, and NB25-C4). Using time-of-addition studies with T-20, we compared the kinetics of HIV-1 entry between reporter viruses pseudotyped with A-R5 Envs containing N362 and PA-R5 Envs lacking N362 (Fig. 8A). In this assay, the maximal delay time after addition of virus to cells when addi- 


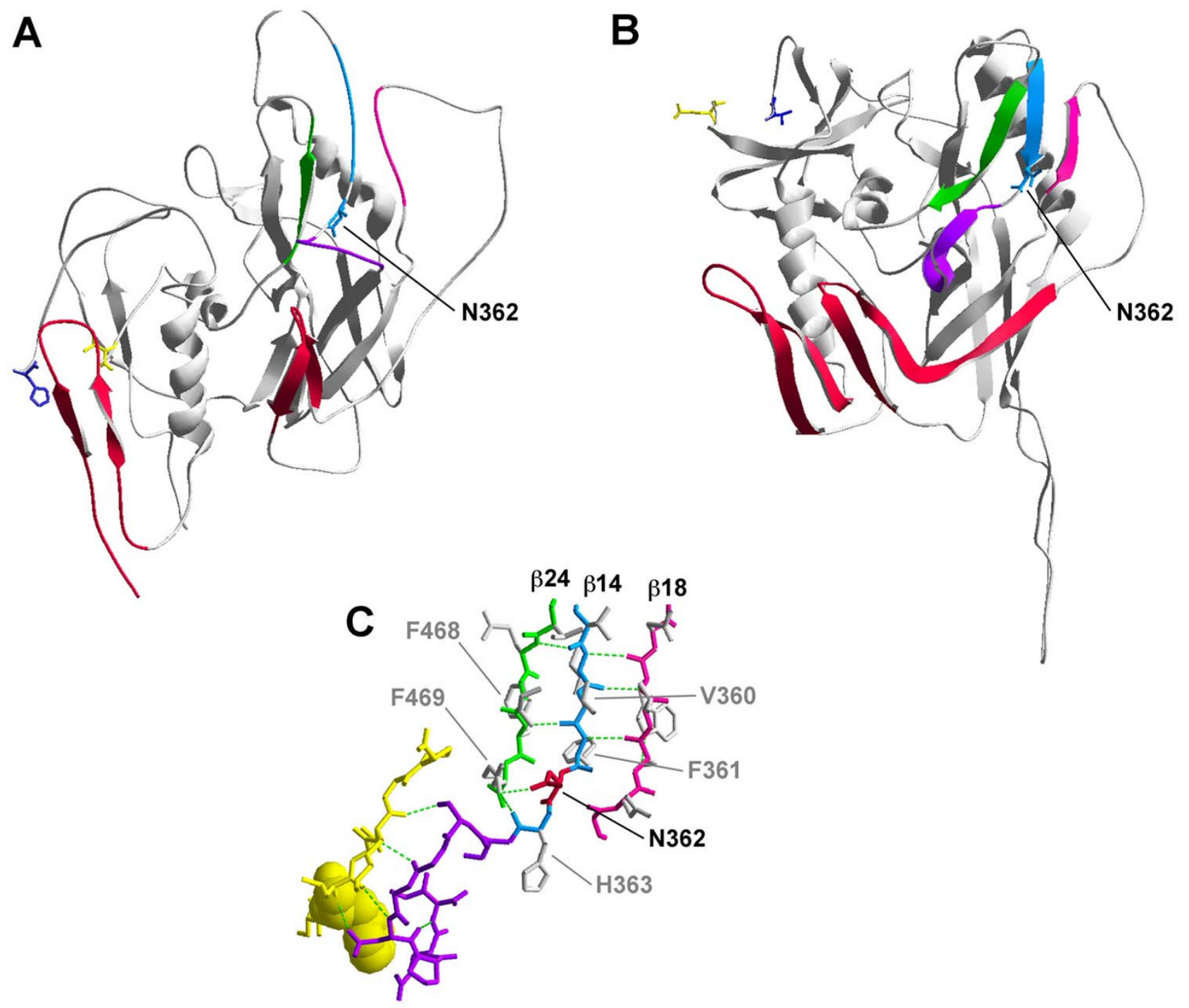

\section{Figure 7}

Structural modelling of N362. Structures of the unliganded SIV gP I 20 (A) and CD4-bound JR-FL gP I 20 (B). The $\beta$ - I4 (cyan), $\beta$ - 18 (pink) and $\beta$-24 strands (green) are highlighted. The CD4 binding loop is highlighted in purple. Asn362 (Thr378 in SIV) is labelled (cyan). Elements of the bridging sheet are highlighted in red. Potential hydrogen bond donors for N362 within the $\beta-14, \beta-18$ and $\beta-24$ strands are shown in (C) and are colored as in (A) and (B). CD4 residues contacting the CD4bs of gP I 20 are colored in yellow, and the molecular surface of Phe43 of CD4 is shown to illustrate the "Phe43 pocket" of the gP I 20 binding site of CD4. N362 is labelled and highlighted in red. Putative hydrogen bond partners are labelled in grey. Hydrogen bonds are depicted as dotted green lines. For simplicity, only the N362 hydrogen bond with R465 is shown.

tion of T-20 can still completely inhibit HIV-1 entry was measured; shorter delay times indicate faster entry kinetics, and longer delay times indicate slower entry kinetics. Viruses pseudotyped with Envs containing N362 had significantly shorter delay times than those pseudotyped with Envs lacking N362. Thus, the presence of N362 in the A-R5 Envs studied is associated with faster entry kinetics. 

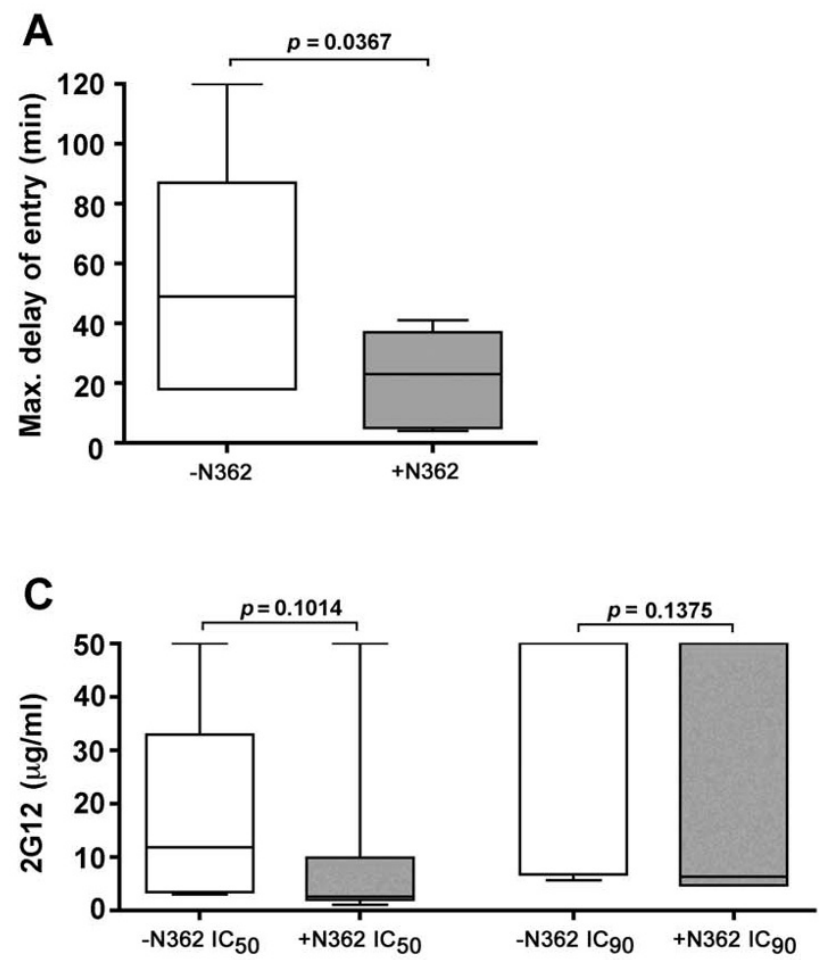

B

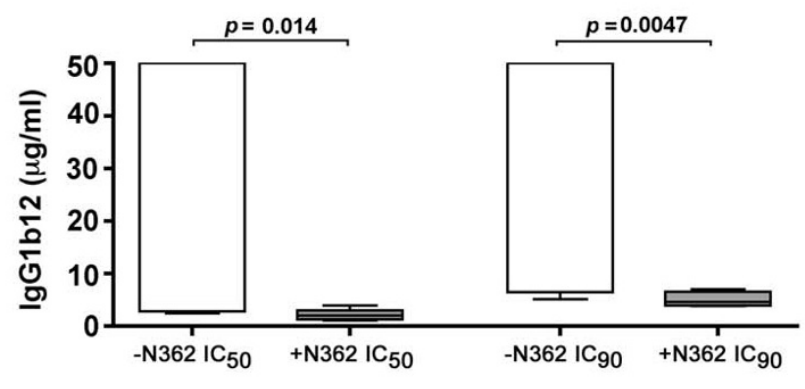

D

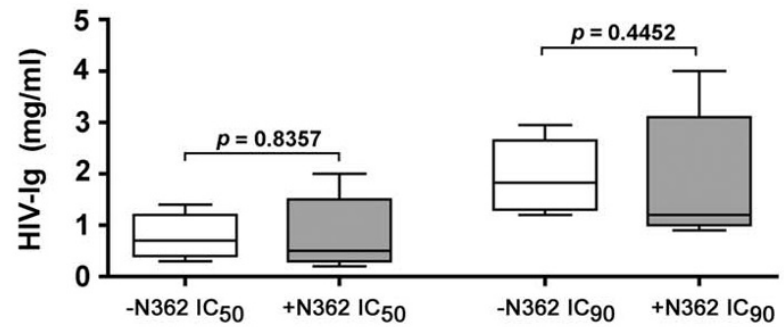

Figure 8

The relationship between N362, HIV-I entry kinetics, and sensitivity to inhibition by neutralizing antibodies. Luciferase reporter viruses pseudotyped with a subset of PA-R5 Envs lacking N362 (NB24-CI, NB24-C2, NB24-C3, NB24-C4, NB25-C2, and NB25-C4) or with a subset of A-R5 Envs containing N362 (NB6-C2, NB6-C3, NB6-C4, NB7-C2, NB7-C4, NB8-C2 and NB8-C4) were produced and quantified as described in the Methods. The kinetics of HIV-I entry by Env-pseudotyped luciferase reporter viruses was determined by time-of-addition studies with T-20, as described in the Methods (A). The results are expressed in minutes as the maximum delay time after addition of virus to JC53 target cells when addition of $50 \mu \mathrm{g}$ per $\mathrm{ml}$ of T-20 can still completely inhibit HIV-I entry (Max. delay of entry), which was determined by least squares regression analysis of time-of-addition curves. The sensitivity of Env-pseudotyped luciferase reporter viruses to neutralization by Env monoclonal antibodies IgGIbI2 (B) or 2 GI2 (C), or by the polyclonal antibody HIV-Ig (D) was determined by calculation of $I_{50}$ and $I C_{90}$ values by least squares analysis of neutralization curves, as described in the Methods. For sensitivity to neutralization by IgGIbI2, four PA-R5 Envs (NB24-CI, NB24-C2, NB24-C3, NB24-C4) had IC ${ }_{50}$ and IC 90 values > $50 \mu g$ per ml, indicating resistance. These Envs were assigned values of $50 \mu \mathrm{g}$ per $\mathrm{ml}$ for the purpose of constructing panel (B). Box plots were constructed from mean values of duplicate experiments with each Env-pseudotyped luciferase reporter virus using Prism version 4.0c (GraphPad Software). Boxes represent upper and lower quartiles and median scores, and whiskers represent minimum and maximum values. The data shown are representative of 2 independent experiments. $P$ values were calculated using a nonparametric Mann-Whitney $U$ test, and values $<0.05$ were considered statistically significant.

\section{A-R5 Envs with N362 have greater CD4bs exposure than PA-R5 Envs lacking N362}

The prediction from structural models that N362 may contribute to stabilizing the CD4-liganded gp120 structure, and the observed faster entry kinetics by Envs containing N362 suggests that N362 may increase the exposure of the CD4bs in gp120. To determine the relationship between the presence of N362 in A-R5 Envs and
CD4bs exposure in gp120, we compared the sensitivity of reporter viruses pseudotyped with A-R5 Envs containing N362 or PA-R5 Envs lacking N362 to neutralization by Env mAbs or HIV-Ig. Viruses pseudotyped with Envs containing N362 were more sensitive to neutralization by the Env mAb IgG1b12 than viruses pseudotyped with Envs lacking N362, as shown by significant differences in the $\mathrm{IC}_{50}$ and $\mathrm{IC}_{90}$ for IgG1b12 (Fig. 8B). In fact, $7 / 7$ of the A- 
R5 Envs tested were highly sensitive to neutralization by IgG1b12 whereas in comparison, only 2/6 PA-R5 Envs were neutralized by IgG1b12 and 4/6 PA-R5 Envs were completely resistant to neutralization by IgG1b12 ( $\mathrm{IC}_{50}$ and $\mathrm{IC}_{90}>50 \mu \mathrm{g}$ per $\mathrm{ml}$ ). However, there were no differences in sensitivity to neutralization by the Env mAb 2G12 (Fig. 8C) or polyclonal HIV-Ig (Fig. 8D) between viruses pseudotyped with Envs either containing or lacking N362. Since the binding site for IgG1b12 overlaps the CD4bs in gp120 [67], these results suggest that the A-R5 Envs containing N362 have increased CD4bs exposure compared to the PA-R5 Envs lacking N362. This conclusion is supported by results of FACS-based antibody binding studies, which showed that A-R5 Envs containing N362 bound to non-saturating concentrations of IgG1b12 more efficiently than PA-R5 Envs lacking N362 when expressed to equivalent levels on the surface of 293T cells (data not shown).

\section{N362 contributes to enhanced fusogenicity of A-R5 Envs in a strain-dependent manner}

To determine whether N362 contributes to enhanced fusogenicity of R5 Envs, a panel of Env mutants was generated that either introduced or removed Asn at position 362 in gp120. Western blot analysis of transfected 293T cells demonstrated equivalent levels of Env expression between wild type Envs and Env mutants (Fig. 9A). The effect of N362 on fusogenicity was first determined in R5 control Envs (Fig. 9B). Wild type ADA and YU2 Envs have N362 and are highly fusogenic, whereas wild type JR-CSF Env lacks N362 and is, by comparison poorly fusogenic (data not shown). Replacement of Asn with Lys at posi-

A

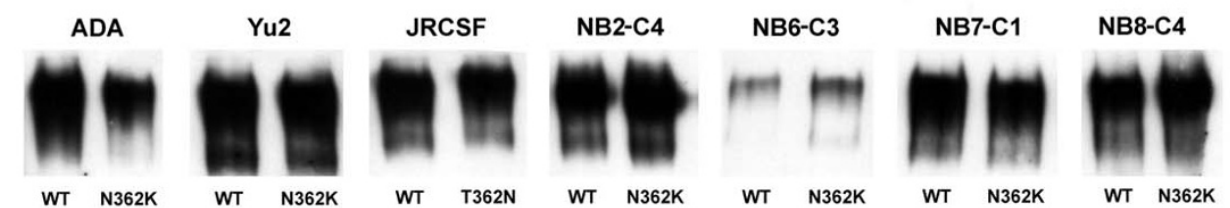

B
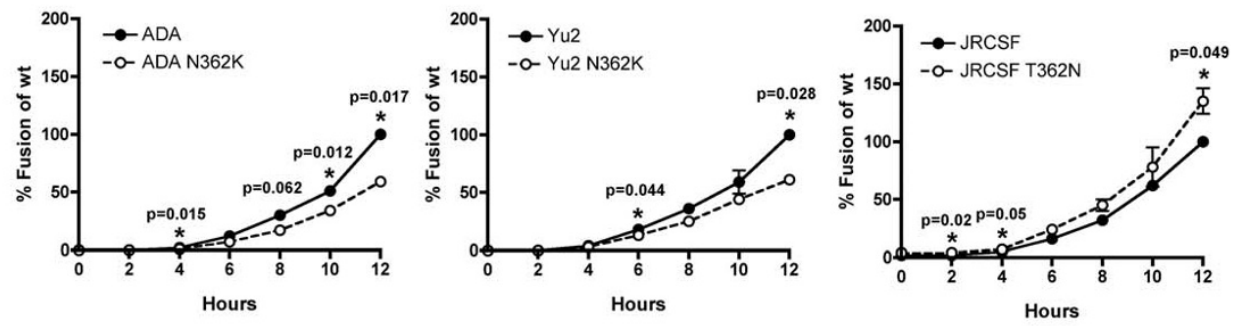

C
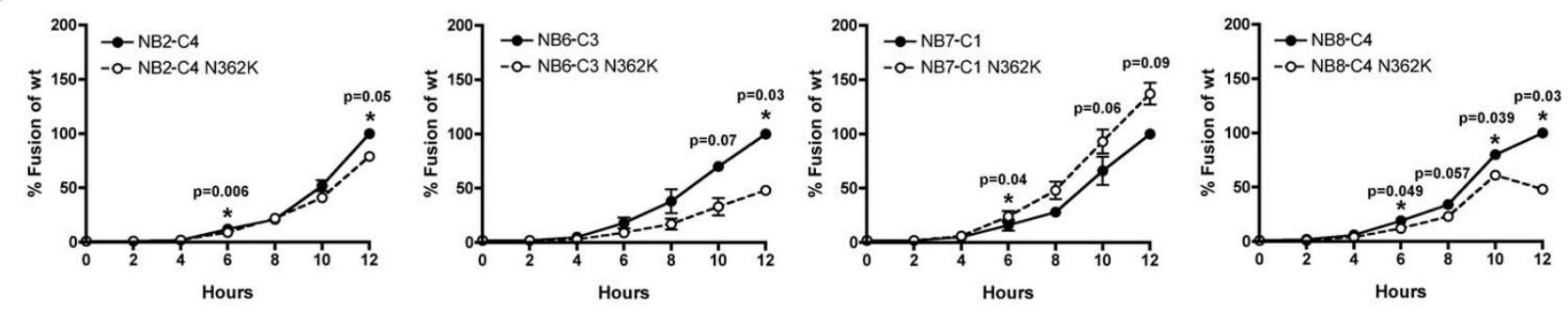

\section{Figure 9}

N362 exerts a strain-dependent enhancement of fusogenicity by R5 Envs. Western blot analysis of 293T cells transfected with wild type and Env mutants (A). Fusion assays were performed using 293T effector cells expressing equivalent levels of wild type or Env mutants generated from control R5 ADA, YU2 and JRCSF Envs (B) or from A-R5 NB2-C4, NB6-C3, NB7$\mathrm{Cl}$ and NB8-C4 Envs (C), and Cf2-Luc target cells expressing CD4 and CCR5 as described in the Methods. Cells were harvested at $2,4,6,8,10$ and $12 \mathrm{~h}$ post-mixing and assayed for luciferase activity. Results are expressed as the percentage of maximal fusion levels attained by the wild type Env clone. Means values of duplicate infections are shown. Error bars represent standard deviations. The results are representative of 2 independent experiments. $P$ values were calculated with a paired t-test, and values $<0.05$ were considered significant*. $P$ values approaching significance are also indicated. 
tion 362 in ADA and YU2 Envs resulted in significant reductions in fusogenicity. Conversely, introducing Asn at position 362 in JR-CSF Env resulted in a significant increase in fusogenicity. Thus, N362 contributes to enhanced fusogenicity of ADA and YU2 Envs and increases fusogenicity of JR-CSF Env.

To better understand the contribution of N362 to enhanced fusogenicity of A-R5 Envs, Asn at position 362 in gp120 of the highly fusogenic NB2-C4, NB6-C3, NB7$\mathrm{C} 1$ and NB8-C4 Envs was replaced with Lys. The removal of Asn at position 362 resulted in significant reductions in fusogenicity of NB2-C4, NB6-C3 and NB8-C4 Envs, but resulted in an apparent increase in fusogenicity by NB7C1 Env (Fig. 9C). However, increased fusogenicity by the NB7-C1 Env mutant was marginal and significant only at one early timepoint $(6 \mathrm{~h})$. Thus, whether substituting Asn for Lys at position 362 modulated fusogenicity of NB7-C1 Env is presently unclear. Together, results of the mutagenesis studies indicate N362 contributes to fusogenicity of the majority of the R5 Envs studied. However, the effect of N362 on fusogenicity of A-R5 Envs appears to be straindependent, suggesting the presence of additional factors contributing to fusogenicity of R5 Envs.

\section{Discussion}

In this study we generated and characterized full-length, functional R5 Env clones derived from well characterized R5 HIV-1 viruses isolated from patients with asymptomatic infection or AIDS. In this panel of Envs, enhanced fusogenicity was a phenotype that distinguished A-R5 from PA-R5 Envs. We showed N362 near the CD4bs in the C3 region of gp120 occurs at higher frequency in A-R5 Envs than PA-R5 Envs and is associated with enhanced fusogenicity, decreased sensitivity to the inhibitory effects of the fusion inhibitor T-20, and increased HIV-1 entry kinetics. Mutagenesis studies showed N362 enhances fusogenicity of A-R5 Envs in a strain-dependent manner. Structural models indicate N362 is located adjacent to the CD4 binding loop of gp120, and together with conformational mapping studies with Env Abs suggest N362 may contribute to enhancement of fusogenicity by promoting greater exposure of the $\mathrm{CD} 4 \mathrm{bs}$ and/or stabilizing the CD4bound Env structure. Together, our results provide evidence that A-R5 Envs have genetic and structural alterations that augment Env-mediated fusion and entry. Enhanced fusogenicity may contribute to pathogenicity of late emerging R5 HIV-1 strains in subjects who persistently maintain R5 HIV-1 variants at late stages of HIV-1 infection.

Increased Env-mediated fusogenicity was found to be a prominent phenotype of the A-R5 Envs studied. Consistent with previous studies that showed membrane fusing capacity to be essential for Env-mediated cytopathicity in vitro [17], the results of our studies suggest increased fusogenicity by A-R5 Envs may reflect an increased ability of A-R5 Envs to cause cytopathic effects. This idea is supported by macaques studies, where passage of chimeric SHIV strains led to enhancement of pathogenicity associated with adaptive changes in Env [18-23]. These mutations arose in the gp120 C2, C3, V3, V4, and gp41 Env regions, resulting in increased Env-mediated fusogenicity that was thought to occur via increased Env-receptor binding. Thus, increased fusogenicity contributes to viral pathogenicity in the macaque model. In addition, increased cytopathicity by an A-R5 Env in SCID-hu mice was reported recently, and thought to occur via increased CCR5 usage [68]. The cytopathic effects of Env-mediated fusogenicity are also evident in humans as MNGC, which are present in autopsy brain tissues of subjects with HIVE [69] and formed by Env-mediated fusion between infected and uninfected macrophage-lineage cells [27]. Multinucleated giant cells in brain are caused predominantly by R5 HIV-1 Envs [44-46,70], which share several features with blood-derived A-R5 Envs such as enhanced fusogenicity $[45,46,71]$, increased sensitivity to neutralization by IgG1b12 [45], and Env structures that enable efficient Env-CD4 interactions [43]. Thus, increased fusogenicity of blood-derived A-R5 Envs may enhance their cytopathic potential. This provides, at least in part, a plausible explanation contributing to CD4+ T-cell depletion that occurs in HIV-1-infected individuals who progress to AIDS whilst exclusively harbouring R5 HIV-1 variants.

Sequence analysis identified the presence of N362 near $\mathrm{CD} 4 \mathrm{bs}$ residues in the $\mathrm{C} 3$ region of gp120 at higher frequency in A-R5 Envs than PA-R5 Envs. N362 was associated with enhanced fusogenicity and increased HIV-1 entry kinetics, suggesting that its presence contributes to the highly fusogenic, A-R5 Env phenotype. Molecular modeling the N362 residue on the unliganded SIV and CD4-liganded HIV-1 JRFL crystal structures places N362 immediately adjacent to the disordered loop region of the CD4bs in the unliganded gp120. In the CD4-liganded gp120, N362 has the potential to form hydrogen bonds with residues from neighbouring strands of the $\beta$-sheet. Alternatively, modeling glycosylated residues on the CD4bound gp120 demonstrated N362 is proximal to N392, another potentially glycosylated residue in the $\beta-18$ strand (data not shown), suggesting N362 may influence the CD4-bound Env structure via interaction with other Nlinked glycans. The latter possibility is supported by recent studies that showed the potentially glycosylated N386 residue in the V4 gp120 region influences CD4bs and IgG1b12 epitope exposure of certain brain-derived Envs [72]. These models suggest that N362 may contribute to stabilizing the CD4-bound state of gp120 by forming intramolecular hydrogen bonds with residues from neigh- 
bouring strands and/or interaction with other glycosylated residues.

In this context A-R5 Envs with N362 may have an enhanced ability to interact with CD4, which is supported by recent studies of the N283 Env variant that is present at high frequency in brain-derived R5 Envs [43,73], and was shown to enhance CD4 binding by forming an additional hydrogen bond with Gln 40 of CD4 [43]. Further supporting this hypothesis are results from recent studies showing increased CD 4 affinity by engineered trimeric gp 120 glycoproteins with enhanced IgG1b12 epitope exposure [74]. Studies of single-molecule bond force spectroscopy in living cells demonstrated that gp120-CD4 binding is shortlived and weak compared with gp120-CD4 complex binding to CCR5 [75], so enhanced Env-CD4 binding may increase the capacity of A-R5 Envs to use CD4 on target cells for HIV-1 entry. Alternatively, since CCR5 is more mobile in the cell membrane than CD4 [76], a more stable gp120-CD4 interaction by A-R5 Envs could potentially permit the Env-CD4 complex to more readily colocalize with CCR5, thus increasing the efficiency of CCR5 usage. Both of these possibilities are supported by our previous studies on the primary R5 HIV-1 isolates used to generate the A-R5 and PA-R5 Env clones, which showed that A-R5 isolates have reduced dependence on both CD4 and CCR5 levels for HIV-1 entry compared to PA-R5 isolates [36]. The possibility that A-R5 Envs may have enhanced CCR5 usage via increased Env-CD4 interactions is supported by recent studies that demonstrated enhanced cytopathicity of an A-R5 Env clone in SCID-hu mice that was thought to occur via increased CCR5 usage [68]. Additional protein binding studies are required to determine whether A-R5 Envs with N362 have increased CD4 binding. However, our results indicating that A-R5 Envs with N362 have greater binding to the Env mAb IgG1b12, which has been mapped to an epitope overlapping the CD4bs [67], and are more sensitive to neutralization by IgG1b12 than PA-R5 Envs lacking N362 support this contention.

Like the effect of the N283 variant in brain-derived R5 Envs on CD4 binding and M-tropism [43], the effect of N362 on augmenting Env-mediated fusogenicity of blood-derived R5 Envs appears to be context dependent, since it did not enhance fusogenicity of all A-R5 Envs (Fig. 9C). Furthermore, a subset of published A-R5 Envs (26\%) lack N362, and a considerable fraction of published PAR5 Envs (49\%) contain N362 [34,38,58-65]. There were no other signature changes that segregated PA-R5 and AR5 Envs, suggesting that cooperative changes that might be required for N362 to mediate enhanced fusogenicity are likely to be strain specific. Cooperative changes may include alterations in hydrogen bond partners of N362 which may affect the ability of N362 to stabilize the CD4- bound Env structure. The relationship between fusogenicity and CD4bs exposure attributable to N362 also appears to be context dependent, since comparisons of fusogenicity and sensitivity to neutralization by IgG1b12 between primary Envs and respective N362 Env mutants (Fig. 9C) showed a direct relationship between alterations in fusogenicity by N362 and sensitivity to IgG1b12 for NB6C3 and NB7-C1 Envs, but not for NB2-C4 and NB8-C4 Envs (data not shown). Thus, the ability of N362 to increase fusogenicity of NB2-C4 and NB8-C4 Envs (Fig. 9C) may depend on other factors to increase exposure of the IgG1b12 epitope. Sequence analysis of the sequentially obtained Envs from subject IK1 demonstrated N362 in both the PA-R5 and A-R5 Envs (data not shown). However, the PA-R5 virus from IK1 differs from the PA-R5 viruses from the cross sectional panel in that it was isolated just prior to the onset of CD4+ T-cell loss and progression toward AIDS [13], whereas the cross sectional panel of PA-R5 viruses were isolated from subjects at earlier stages of asymptomatic infection [34]. Therefore, although the A-R5 viruses from both panels were isolated from patients with AIDS, there is considerable heterogeneity among the PA-R5 viruses across the panels with respect to the stage of asymptomatic HIV-1 infection from which they were isolated. It is possible that N362 may occur with different frequencies in PA-R5 Envs isolated at different stages of asymptomatic infection. Of note, even though the A-R5 Envs from IK1 were more fusogenic than PA-R5 Envs from this subject, the fusogenicity of the PAR5 Envs from IK1 was comparable to that of the A-R5 Envs from the cross sectional cohort. Thus, although N362 is associated with enhanced fusogenicity of A-R5 Envs, additional Env changes present in A-R5 Envs of IK1 may increase fusogenicity further.

Whether R5 HIV-1 strains may acquire N362 through adaptive changes and contribute to the pathogenesis of R5 HIV-1 infection in vivo is presently unclear. However, in support of this hypothesis, longitudinal analysis of R5 Env sequences in two individuals infected from the same source showed maintenance of N362 in a rapid progressor whereas a nonprogressing subject continued to maintain a mixture of N362, K362, S362, T362 and F362 amino acid variants [64]. Thus, N362 may be selected in vivo and potentially contribute to progressive R5 HIV-1 infection in a host-dependent manner. It is also presently unclear whether phenotypic differences in R5 Envs attributable to N362 are likely to be relevant in vivo, since in some assays only relatively small differences were observed. More detailed longitudinal studies on virus derived from plasma of subjects with progressive R5 HIV-1 infection are necessary to determine the temporal nature of $\mathrm{N} 362$ acquisition and it's effect on HIV-1 pathogenicity in vivo. 
In conclusion, enhanced fusogenicity is a phenotype of AR5 Envs which is associated with N362 in gp120, and linked to increased entry kinetics and increased exposure of the CD4bs in gp120. N362 contributes to enhanced fusogenicity of A-R5 Envs in a strain-dependent manner. These results lead to a better understanding of the mechanisms contributing to CD4+ T-cell depletion in subjects who progress to AIDS whilst exclusively harbouring R5 HIV-1 variants.

\section{Methods \\ Virus isolates}

In this study, we utilized two independent panels of well characterized primary R5 HIV-1 isolates. The first was a cross sectional panel of R5 HIV-1 viruses isolated from immunocompetent subjects with asymptomatic HIV-1 infection ( $\mathrm{n}=4$ isolates) or from patients with AIDS ( $\mathrm{n}=$ 4 isolates) [34,36]. The second comprised R5 HIV-1 viruses isolated sequentially from one subject (IK1) from chronic HIV-1 infection to AIDS ( $\mathrm{n}=2$ isolates) $[13,42]$. For the purpose of this study, the viruses isolated from patients with AIDS are referred to as AIDS R5 (A-R5) viruses, and those isolated from the earlier times are referred to as pre-AIDS R5 (PA-R5) viruses.

A detailed characterization of the cross sectional panel of R5 HIV-1 viruses including analysis of quasispecies diversity, coreceptor usage, replication kinetics, and clinical characteristics of the subjects from whom they were isolated, has been described previously [34,36]. Briefly, the PA-R5 viruses NB23, NB24, NB25 were isolated from peripheral blood mononuclear cells (PBMC) of individuals with CDC category II disease (asymptomatic infection) with CD4 counts of $>500$ cells/ $\mu$ l. PA-R5 virus NB27 was isolated from PBMC of an individual with CDC category I disease (acute seroconversion) with CD4 count of $>750$ cells/ $\mu$ l. A-R5 viruses NB2, NB6, NB7 and NB8 were isolated from PBMC of individuals with CDC category IV disease (AIDS) and CD4 counts of $<50$ cells $/ \mu l$.

The longitudinal R5 HIV-1 viruses isolated from sequential PBMC samples from subject IK1 are designated IK1PA and IK1-A. These viruses were referred to previously as 435-531 and 435-3415, respectively [13]. A detailed characterization of these HIV-1 isolates including analysis of quasispecies diversity, coreceptor usage, replication kinetics, and clinical characteristics of the subjects from whom they were isolated, has been described previously $[13,42]$.

\section{Cells}

PBMC were purified from blood of healthy HIV-1-negative donors, stimulated with $5 \mu \mathrm{g}$ of phytohemagglutinin (PHA) (Sigma, St. Louis, MO) per ml for 3 days, and cultured in RPMI 1640 medium supplemented with $10 \%$ (vol/vol) fetal calf serum (FCS), $100 \mu \mathrm{g}$ of penicillin and streptomycin per $\mathrm{ml}$, and $20 \mathrm{U}$ of interleukin-2 (IL-2) (Roche, Basel, Switzerland) per ml. Cf2-Luc cells [25] are derived from the Cf2th canine thymocyte cell line [77], and stably express the luciferase gene under the control of the HIV-1 long terminal repeat and were cultured in Dulbecco modified Eagle medium (DMEM) supplemented with $10 \%$ (vol/vol) FCS, $100 \mu \mathrm{g}$ of penicillin and streptomycin per $\mathrm{ml}$, and $0.7 \mathrm{mg}$ of G418 per ml. Cf2-CD4 cells [78] were cultured in DMEM supplemented with $10 \%$ (vol/vol) FCS, $100 \mu \mathrm{g}$ of penicillin and streptomycin per $\mathrm{ml}$, and $0.5 \mathrm{mg}$ of G418 per ml. Cf2-CD4/CCR5 cells [79] were cultured in DMEM supplemented with $10 \%$ (vol/ vol) FCS, $100 \mu \mathrm{g}$ of penicillin and streptomycin per ml, $0.5 \mathrm{mg}$ of G418 per $\mathrm{ml}$, and $0.1 \mathrm{mg}$ of hygromycin per $\mathrm{ml}$. Cf2-CD4/CXCR4 cells were constructed by transduction of the Cf2-CD4 cell line [78] with pBABE-puro vectors expressing CXCR4 $[80,81]$ followed by selection and expansion in DMEM supplemented with $10 \%$ (vol/vol) FCS, $100 \mu \mathrm{g}$ of penicillin and streptomycin per $\mathrm{ml}, 0.5 \mathrm{mg}$ of G418 per ml, and $1 \mu \mathrm{g}$ of puromycin per ml. Cf2-CD4/ CCR5/CXCR4 cells [56] were cultured in DMEM supplemented with $10 \%$ (vol/vol) FCS, $100 \mu \mathrm{g}$ of penicillin and streptomycin per $\mathrm{ml}, 0.5 \mathrm{mg}$ of G418 per $\mathrm{ml}, 0.1 \mathrm{mg}$ hygromycin per $\mathrm{ml}$, and $1 \mu \mathrm{g}$ puromycin per $\mathrm{ml}$. JC53 cells are derived from the HeLa cell line and stably express high levels of CD4, CXCR4 and CCR5 on the cell surface [82], and were cultured in DMEM supplemented with $10 \%$ (vol/vol) FCS, and $100 \mu \mathrm{g}$ of penicillin and streptomycin per ml. 293T cells were cultured in DMEM supplemented with $10 \%$ (vol/vol) FCS, and $100 \mu \mathrm{g}$ of penicillin and streptomycin per $\mathrm{ml}$.

\section{PCR amplification, HIV-I Env cloning, identification of functional Envs, and sequence analysis}

Genomic DNA was extracted from PBMC infected with NB2, NB6, NB7, NB8, NB23, NB24, NB25 and NB27 primary isolates using a QIAmp genomic DNA purification kit (Qiagen) according to the manufacturers' protocol. Viral RNA was isolated from $1 \mathrm{ml}$ of IK1-PA and IK1-A primary isolates using a QIAmp UltraSense viral RNA isolation kit (Qiagen), according to the manufacturers' instructions. CDNA was reversed transcribed from viral RNA using SuperscriptIII RT (Invitrogen) and random hexamers, according to the manufacturers' protocol. An approximately $2.1 \mathrm{~kb}$ fragment spanning the KpnI to BamHI restriction sites in HIV-1 env (corresponding to nucleotides 6348 to 8478 in HXB2) was amplified by PCR using nested primers and Expand high fidelity DNA polymerase (Roche diagnostics), as described previously $[56,57]$. The outer primers were env1A and env1M [83], and the inner primers were Env-KpnI and Env-BamHI $[56,57]$. PCR cycling consisted of an initial denaturation step at $94^{\circ} \mathrm{C}$ for $2 \mathrm{~min}$ followed by 9 cycles of $94^{\circ} \mathrm{C}$ for 15 $\mathrm{s}, 60^{\circ} \mathrm{C}$ for $30 \mathrm{~s}$ and $72^{\circ} \mathrm{C}$ for $2 \mathrm{~min}$, then a further 20 
cycles of $94^{\circ} \mathrm{C}$ for $15 \mathrm{~s}, 60^{\circ} \mathrm{C}$ for $30 \mathrm{~s}$ and $72^{\circ} \mathrm{C}$ for $2 \mathrm{~min}$ but with a $5 \mathrm{~s}$ increasing extension time for each cycle, followed by a final extension at $72^{\circ} \mathrm{C}$ for $7 \mathrm{~min}$. The products of 3 independent PCR reactions were purified and pooled, then cloned into the pSVIII-HXB2 Env expression plasmid [83] by replacement of the $2.1 \mathrm{~kb} K p n \mathrm{I}$ to BamHI HXB2 env fragment. Thus, the resulting Env clones contain the entire gp160 coding region of primary virusderived env genes except for 36 amino acids at the $\mathrm{N}$ terminus and 105 amino acids at the $\mathrm{C}$ terminus, which are derived from HXB2. Three to 4 functional Env clones from each virus were identified by the ability to support entry when pseudotyped onto Env-deficient GFP reporter viruses and used in single round entry assays in JC53 or Cf2-CD4/CCR5/CXCR4 cells, and by Western blot analysis of gp120/gp160 in transfected 293T cells and fusion assays. The coreceptor usage of functional Env clones was verified by single round entry assays in Cf2-CD4/CCR5 and Cf2-CD4/CXCR4 cells infected with Env-pseudotyped GFP reporter viruses, as described previously $[56,84]$. Envs were sequenced by Big Dye terminator sequencing (Applied Biosystems) and analyzed using a model 3100 Genetic Analyzer (Applied Biosystems).

\section{Env mutagenesis}

Mutagenesis to introduce or remove Asn at position 362 in gp120 was performed using the QuikChange II sitedirected mutagenesis kit (Stratagene) according to the manufacturer's instructions. Mutagenesis primers were designed to span the CD4 binding loop region corresponding to nucleotides 7297 to 7325 of HXB2 for control R5 Env clones ADA, YU2, and JR-CSF and primary AR5 Env clones NB2-C4, NB6-C3, NB7-C1 and NB8-C4. The primers used in the mutagenesis studies are shown in Additional file 1. Envs mutants were sequenced to confirm the presence of the mutated residue.

\section{Western blot analysis}

For analysis of Env expression, 293T cells were co-transfected with $8 \mu \mathrm{g}$ of pSVIII-Env plasmid and $2 \mu \mathrm{g}$ pSVL-Tat plasmid using the calcium phosphate method. At $72 \mathrm{~h}$ after transfection, cells were rinsed twice in PBS and resuspended in $400 \mu \mathrm{l}$ of ice cold lysis buffer (0.5\% [vol/vol] NP-40; $0.5 \%$ [wt/vol] sodium deoxycholate; $50 \mathrm{mM}$ $\mathrm{NaCl} ; 25 \mathrm{mM}$ Tris-HCl [pH 8.0]; $10 \mathrm{mM}$ EDTA, $5 \mathrm{mM}$ benzamidine $\mathrm{HCl}$; and a cocktail of protease inhibitors) for $10 \mathrm{~min}$, followed by centrifugation at $15,300 \times \mathrm{g}$ for 10 min at $4{ }^{\circ} \mathrm{C}$ to remove cellular debris. Cell lysates were separated in $8.5 \%$ (wt/vol) sodium dodecyl sulfate-polyacrylamide gel electrophoresis (SDS-PAGE) gels and analyzed by Western blotting using rabbit anti-gp120 polyclonal antisera. Env proteins were visualized using horseradish peroxidase-conjugated anti-rabbit immunoglobulin G antibody and enhanced chemiluminescence (Promega).

\section{Fusion assays}

Fusion assays were conducted as described previously $[43,45,71,85]$ with minor modifications. Briefly, $293 \mathrm{~T}$ effector cells co-transfected with $3.4 \mu \mathrm{g}$ of Env-expressing plasmid and $0.6 \mu \mathrm{g}$ pSVL-Tat plasmid using Lipofectamine 2000 (Invitrogen) were mixed with Cf2-Luc target cells that had been co-transfected with $2 \mu \mathrm{g}$ of pcDNA3-CD4 and $6 \mu \mathrm{g}$ of pcDNA3-CCR5, and incubated at $37^{\circ} \mathrm{C}$ in replicate wells of 96 -well tissue culture plates containing $200 \mu \mathrm{l}$ of culture medium. Cells from replicate wells were harvested at 2, 4, 6, 8, 10 and $12 \mathrm{~h}$ post-mixing and assayed for luciferase activity (Promega) according to the manufacturers' protocol. 293T cells transfected with pSVL-Tat alone were used as negative controls to determine the background level of luciferase activity. In experiments analysing the ability of T-20 to inhibit Env function in fusion assays, the $10 \mathrm{~h}$ time point was used for analysis. To control for cell surface Env expression levels in $293 \mathrm{~T}$ effector cells, Env expression was measured by flow cytometry using pooled AIDS serum and a FITC-conjugated anti-human $\mathrm{F}(\mathrm{ab}) 2$ Ig (Chemicon). To account for both the number of Env expressing cells and the fluorescence intensity, the relative fluorescence was calculated from fluorescence-activated cell sorter (FACS) profiles by multiplying the percentage Env-expressing cells by the mean channel fluorescence, as described previously [86].

\section{Production and quantitation of Env-pseudotyped, luciferase reporter viruses}

Env-pseudotyped, luciferase reporter viruses were produced by transfection of $293 \mathrm{~T}$ cells with pCMV $\Delta \mathrm{P} 1 \Delta$ envpA, pHIV-1Luc and pSVIII-Env plasmids using Lipofectamine 2000 (Invitrogen) at a ratio of 1:3:1, as described previously $[56,79,87,88]$. Supernatants were harvested $48 \mathrm{~h}$ later and filtered through $0.45 \mu \mathrm{m}$ filters. Recombinant luciferase reporter viruses were ultracentrifuged through a $25 \%$ (vol/vol) sucrose cushion at 25,000 rpm for $2 \mathrm{~h}$ at $4^{\circ} \mathrm{C}$ using a Beckman Ultra high speed centrifuge and a SW28 rotor, resuspended in $2 \mathrm{ml}$ culture medium, aliquotted and stored at $-80^{\circ} \mathrm{C}$. The $\mathrm{TCID}_{50}$ of virus stocks was determined by titration in JC53 cells.

\section{Analysis of HIV-I entry kinetics}

Time-of-addition experiments using the HIV-1 fusion inhibitor T-20 and Env-pseudotyped luciferase reporter viruses were conducted to measure the entry kinetics of Env. This method was based on that recently described by Olivieri et al., [68] with the following modifications. Two hundred $\mathrm{TCID}_{50}$ of Env-pseudotyped luciferase reporter virus (equating to an MOI of 0.02 ) was added to replicate wells of JC53 cells. Fifty micrograms of T-20 per ml was added to the replicate wells at $0,10,20,30,40,5060$ and 120 min post-infection. This concentration of T-20 was empirically determined to be completely inhibitory for each of the Env-pseudotyped luciferase reporter viruses 
tested when added to virus before infection of JC53 cells (data not shown). After $2 \mathrm{~h}$, the virus inoculum was removed and the cells were washed twice prior to addition of fresh culture medium containing $50 \mu \mathrm{g}$ of T-20 per ml. Cells were harvested $48 \mathrm{~h}$ later and assayed for luciferase activity (Promega) according to the manufacturers' protocol. The maximum delay time after addition of virus to JC53 cells when addition of $50 \mu \mathrm{g}$ per $\mathrm{ml}$ of T-20 can still completely inhibit HIV-1 entry was calculated (Max. delay of entry). For these analyses, inhibition of entry was defined as luciferase activity measurements $<3$-fold above background, as determined using reporter virus pseudotyped with a non-functional Env ( $\Delta K S$ Env) [25]. Luciferase activity was plotted against time of T-20 addition using Prism version 4.0c (GraphPad Software, San Diego, CA.). Data were fitted with a nonlinear function, and Max. delay of entry was calculated by least squares regression analysis of time-of-addition curves. Envs with lower Max. delay of entry values were interpreted to have faster entry kinetics, and vice-versa.

\section{Neutralization assays}

Human mAbs against HIV-1 gp120 (IgG1b12, 2G12) and the polyclonal antibody HIV-Ig have been described previously [89-93]. The ability of these antibodies to neutralize the infectivity of Env-pseudotyped luciferase reporter viruses was assayed using JC53 cells. Two hundred TCID of each Env-pseudotyped luciferase reporter virus (equating to an MOI of 0.02) was incubated with 10-fold increasing concentrations of each mAb $(0.0005$ to $50 \mu \mathrm{g} /$ $\mathrm{ml}$ ) or HIV-Ig ( 1 to $10,000 \mu \mathrm{g} / \mathrm{ml}$ ) for $1 \mathrm{~h}$ at $37^{\circ} \mathrm{C}$. The virus-Ab mixtures were then used to inoculate JC53 cells overnight at $37^{\circ} \mathrm{C}$. Cells were rinsed twice with culture medium to remove residual virus inoculum and incubated a further $48 \mathrm{~h}$ at $37^{\circ} \mathrm{C}$. Virus infectivity was then measured by assaying luciferase activity in cell lysates (Promega), according to the manufacturers' protocol. Negative controls included mock-infected cells that were incubated with culture medium instead of virus, and cells treated with luciferase reporter virus pseudotyped with the non-functional $\Delta K S$ Env. After subtracting background luciferase activity, the amount of luciferase activity in the presence of antibody was expressed as a percentage of the amount produced in control cultures containing no antibody. The percent inhibition was calculated by subtracting this number from 100. Data were fitted with a nonlinear function, and fifty percent inhibitory concentration $\left(\mathrm{IC}_{50}\right)$ and $\mathrm{IC}_{90}$ values were calculated by least squares regression analysis of inhibition curves, as described previously $[36,45,85]$.

\section{Structural modeling}

Proteins structures of unliganded SIV gp120 (2BF1) $[66,94]$ and the V3 loop-containing protein structure of JR-FL (2B4C) [95] were obtained from the RCSB Protein
Data Bank. Structural modelling was performed using Swiss PDB Viewer. Hydrogen bond analysis was performed using CSU software [96].

\section{Nucleotide sequence accession numbers}

The Env nucleotide sequences reported here have been assigned GenBank accession numbers EU308533 to EU308568.

\section{Competing interests}

The author(s) declare that they have no competing interests.

\section{Authors' contributions}

JS, MJC, LRG and SS carried out the Env cloning; IS and AE performed fusion assays; JS, AE and MR produced Envpseudotyped reporter viruses and conducted entry assays; JS, RLD and DG performed structural analyses; NS and BW performed the Env sequencing; SLW, IK, E-MF and ALC contributed clinical data; DFJP supplied essential reagents and contributed intellectually, JS and PRG designed the study, interpreted the data and wrote the manuscript; all authors helped edit the manuscript and have read and approved the final version.

\section{Additional material}

\section{Additional file 1}

Primers used for Env mutagenesis. The sequences of the oligonucleotide primers used to synthesize Env mutants are shown.

Click here for file

[http://www.biomedcentral.com/content/supplementary/17424690-4-89-S1.jpeg]

\section{Acknowledgements}

We thank J. Sodroski and B. Etemad-Gilbertson for providing Cf2-CD4, Cf2-CD4/CCR5 and Cf2-Luc cells, J. Sodroski for providing PSVIII-HXB2 Env, pSVIII- $\Delta$ KS Env, pcDNA3-CD4, pcDNA3-CCR5, pCMV $\Delta \mathrm{PI} \Delta$ envpA, and pHIV-I Luc plasmids, $\mathrm{H}$. Gottlinger for providing PSVL-Tat plasmid, E. Dax, K. Wilson and D. McPhee for providing pooled AIDS serum, D. Kabat for providing JC53 cells, and C. Cherry for advice with statistical analyses. The following reagents were obtained through the NIH AIDS Research and Reference Reagent Program, Division of AIDS, NIAID, NIH: HIV-I gPI 20 monoclonal antibody (2GI2) from H. Katinger; HIV-I gP I 20 monoclonal antibody (lgG Ib 2 ) from D. Burton and C. Barbas; HIV-lg from NABI and NHLBI; and T-20 fusion inhibitor from Roche.

This study was supported, in part, from a multi-center program grant from the Australian National Health and Medical Research Council (NHMRC) to SLW and ALC (358399), and grants from the Australian NHMRC (25I 520 and 433915) and NIH/NIAID (Al054207) to PRG. RLD and DG were supported by NIH NS37277. JS and LRG are supported by Australian NHMRC Dora Lush Biomedical Research Scholarships. PRG is the recipient of an Australian NHMRC R. Douglas Wright Biomedical Career Development Award. 


\section{References}

I. Berger EA, Murphy PM, Farber JM: Chemokine receptors as HIVI coreceptors: roles in viral entry, tropism, and disease. Annu Rev Immunol 1999, I 7:657-700.

2. Doms RW, Trono D: The plasma membrane as a combat zone in the HIV battlefield. Genes Dev 2000, I4(2I):2677-2688.

3. Moore JP, Kitchen SG, Pugach P, Zack JA: The CCR5 and CXCR4 coreceptors--central to understanding the transmission and pathogenesis of human immunodeficiency virus type I infection. AIDS Res Hum Retroviruses 2004, 20( I): I I I-I 26.

4. Connor RI, Sheridan KE, Ceradini D, Choe S, Landau NR: Change in coreceptor use coreceptor use correlates with disease progression in HIV-I--infected individuals. J Exp Med 1997, I 85(4):62I-628.

5. Bjorndal A, Deng $H$, Jansson M, Fiore JR, Colognesi C, Karlsson A, Albert J, Scarlatti G, Littman DR, Fenyo EM: Coreceptor usage of primary human immunodeficiency virus type I isolates varies according to biological phenotype. J Virol 1997, 7 I ( I 0):7478-7487.

6. Karlsson A, Parsmyr K, Aperia K, Sandstrom E, Fenyo EM, Albert J: MT-2 cell tropism of human immunodeficiency virus type isolates as a marker for response to treatment and development of drug resistance. J Infect Dis I994, I 70(6): I367-I375.

7. Koot M, Keet IP, Vos AH, de Goede RE, Roos MT, Coutinho RA, Miedema F, Schellekens PT, Tersmette M: Prognostic value of HIV-I syncytium-inducing phenotype for rate of CD4+ cell depletion and progression to AIDS. Ann Intern Med 1993, I | 8(9):68|-688.

8. Tersmette M, Gruters RA, de Wolf F, de Goede RE, Lange JM, Schellekens PT, Goudsmit J, Huisman HG, Miedema F: Evidence for a role of virulent human immunodeficiency virus (HIV) variants in the pathogenesis of acquired immunodeficiency syndrome: studies on sequential HIV isolates. J Virol 1989, 63(5):2II8-2I25.

9. de Roda Husman AM, Schuitemaker $\mathrm{H}$ : Chemokine receptors and the clinical course of HIV-I infection. Trends Microbiol 1998, 6(6):244-249.

10. Jansson M, Backstrom E, Bjorndal A, Holmberg V, Rossi P, Fenyo EM, Popovic M, Albert J, Wigzell $\mathrm{H}$ : Coreceptor usage and RANTES sensitivity of non-syncytium-inducing HIV-I isolates obtained from patients with AIDS. J Hum Virol 1999, 2(6):325-338.

II. Jansson M, Popovic M, Karlsson A, Cocchi F, Rossi P, Albert J, Wigzell $\mathrm{H}$ : Sensitivity to inhibition by beta-chemokines correlates with biological phenotypes of primary HIV-I isolates. Proc Natl Acad Sci USA 1996, 93(26): I5382-I5387.

12. de Roda Husman AM, van Rij RP, Blaak H, Broersen S, Schuitemaker $\mathrm{H}$ : Adaptation to promiscuous usage of chemokine receptors is not a prerequisite for human immunodeficiency virus type I disease progression. J Infect Dis 1999, I80(4): I I06-I I I5.

13. Karlsson I, Antonsson L, Shi Y, Oberg M, Karlsson A, Albert J, Olde $B$, Owman C, Jansson M, Fenyo EM: Coevolution of RANTES sensitivity and mode of CCR5 receptor use by human immunodeficiency virus type I of the R5 phenotype. J Virol 2004, 78(2I): I I807-II8I5

14. Koning FA, Kwa D, Boeser-Nunnink B, Dekker J, Vingerhoed J, Hiemstra $H$, Schuitemaker $H$ : Decreasing sensitivity to RANTES (regulated on activation, normally $T$ cell-expressed and secreted) neutralization of CC chemokine receptor 5-using, non-syncytium-inducing virus variants in the course of human immunodeficiency virus type I infection. I Infect Dis 2003, I 88(6):864-872.

15. Gorry PR, Churchill M, Crowe SM, Cunningham AL, Gabuzda D: Pathogenesis of macrophage tropic HIV. Curr HIV Res 2005, 3(I):53-60.

16. Sodroski J, Goh WC, Rosen C, Campbell K, Haseltine WA: Role of the HTLV-III/LAV envelope in syncytium formation and cytopathicity. Nature 1986, 322(6078):470-474

17. LaBonte JA, Patel T, Hofmann W, Sodroski J: Importance of membrane fusion mediated by human immunodeficiency virus envelope glycoproteins for lysis of primary CD4-positive T cells. J Virol 2000, 74(22): 10690-10698.

18. Cayabyab M, Karlsson GB, Etemad-Moghadam BA, Hofmann W, Steenbeke T, Halloran M, Fanton JW, Axthelm MK, Letvin NL, Sodroski JG: Changes in human immunodeficiency virus type I envelope glycoproteins responsible for the pathogenicity of a multiply passaged simian-human immunodeficiency virus (SHIV-HXBc2). J Virol 1999, 73(2):976-984.

19. Karlsson GB, Halloran M, Li J, Park IW, Gomila R, Reimann KA Axthelm MK, Iliff SA, Letvin NL, Sodroski J: Characterization of molecularly cloned simian-human immunodeficiency viruses causing rapid CD4+ lymphocyte depletion in rhesus monkeys. J Virol 1997, 7 I(6):4218-4225.

20. Karlsson GB, Halloran M, Schenten D, Lee J, Racz P, Tenner-Racz K, Manola J, Gelman R, Etemad-Moghadam B, Desjardins E, Wyatt R, Gerard NP, Marcon L, Margolin D, Fanton J, Axthelm MK, Letvin NL, Sodroski J: The envelope glycoprotein ectodomains determine the efficiency of CD4+ T lymphocyte depletion in simian-human immunodeficiency virus-infected macaques. J Exp Med 1998, I88(6): II59-II7I.

21. Stephens EB, Joag SV, Sheffer D, Liu ZQ, Zhao L, Mukherjee S, Foresman L, Adany I, Li Z, Pinson D, Narayan O: Initial characterization of viral sequences from a SHIV-inoculated pig-tailed macaque that developed AIDS. I Med Primatol 1996 25(3): $175-185$.

22. Stephens EB, Mukherjee S, Sahni M, Zhuge W, Raghavan R, Singh DK, Leung K, Atkinson B, Li Z, Joag SV, Liu ZQ, Narayan O: A cell-free stock of simian-human immunodeficiency virus that causes AIDS in pig-tailed macaques has a limited number of amino acid substitutions in both SIVmac and HIV-I regions of the genome and has offered cytotropism. Virology 1997, 23 I (2):3|3-32|.

23. Liu ZQ, Muhkerjee S, Sahni M, McCormick-Davis C, Leung K, Li Z, Gattone VH 2nd, Tian C, Doms RW, Hoffman TL, Raghavan R, Narayan O, Stephens EB: Derivation and biological characterization of a molecular clone of SHIV(KU-2) that causes AIDS, neurological disease, and renal disease in rhesus macaques. Virology 1999, 260(2):295-307.

24. Etemad-Moghadam B, Rhone D, Steenbeke T, Sun Y, Manola J, Gelman R, Fanton JW, Racz P, Tenner-Racz K, Axthelm MK, Letvin NL, Sodroski J: Membrane-fusing capacity of the human immunodeficiency virus envelope proteins determines the efficiency of CD+ $T$-cell depletion in macaques infected by a simianhuman immunodeficiency virus. J Virol 200 I, 75( I 2):5646-5655.

25. Etemad-Moghadam B, Sun Y, Nicholson EK, Fernandes M, Liou K, Gomila R, Lee J, Sodroski J: Envelope glycoprotein determinants of increased fusogenicity in a pathogenic simian-human immunodeficiency virus (SHIV-KB9) passaged in vivo. J Virol 2000, 74(9):4433-4440.

26. Si Z, Gorry P, Babcock G, Owens CM, Cayabyab M, Phan N, Sodroski J: Envelope glycoprotein determinants of increased entry in a pathogenic simian-human immunodeficiency virus (SHIV$\mathrm{HXBc2P} 3.2)$ passaged in monkeys. AIDS Res Hum Retroviruses 2004, 20(2):163-173.

27. Gonzalez-Scarano F, Martin-Garcia J: The neuropathogenesis of AIDS. Nat Rev Immunol 2005, 5(I):69-8I.

28. Glushakova S, Baibakov B, Margolis LB, Zimmerberg J: Infection of human tonsil histocultures: a model for HIV pathogenesis. Nature Med 1995, I ( I 2): | 320-I 322.

29. Glushakova S, Grivel JC, Fitzgerald W, Sylwester A, Zimmerberg J, Margolis LB: Evidence for the HIV-I phenotype switch as a causal factor in acquired immunodeficiency. Nature Med 1998, 4(3):346-349.

30. Picchio GR, Gulizia RJ, Wehrly K, Chesebro B, Mosier DE: The cell tropism of human immunodeficiency virus type I determines the kinetics of plasma viremia in SCID mice reconstituted with human peripheral blood leukocytes. J Virol I998, 72(3):2002-2009.

31. Harouse JM, Gettie A, Tan RC, Blanchard J, Cheng-Mayer C: Distinct pathogenic sequela in rhesus macaques infected with CCR5 or CXCR4 utilizing SHIVs. Science I999, 284(54I5):8|6-8I9.

32. Fais S, Lapenta C, Santini SM, Spada M, Parlato S, Logozzi M, Rizza P, Belardelli F: Human immunodeficiency virus type I strains R5 and $X 4$ induce different pathogenic effects in hu-PBL-SCID mice, depending on the state of activation/differentiation of human target cells at the time of primary infection. J Virol 1999, 73(8):6453-6459.

33. Grivel JC, Margolis LB: CCR5- and CXCR4-tropic HIV-I are equally cytopathic for their $\mathrm{T}$-cell targets in human lymphoid tissue. Nature Med 1999, 5(3):344-346.

34. Li S, Juarez J, Alali M, Dwyer D, Collman R, Cunningham A, Naif HM: Persistent CCR5 utilization and enhanced macrophage tro- 
pism by primary blood human immunodeficiency virus type $\mathrm{I}$ isolates from advanced stages of disease and comparison to tissue-derived isolates. J Virol 1999, 73( I 2):974|-9755.

35. Tuttle DL, Anders CB, Aquino-De Jesus MJ, Poole PP, Lamers SL, Briggs DR, Pomeroy SM, Alexander L, Peden KW, Andiman WA, Sleasman JW, Goodenow MM: Increased replication of non-syncytium-inducing HIV type I isolates in monocyte-derived macrophages is linked to advanced disease in infected children. AIDS Res Hum Retroviruses 2002, I 8(5):353-362.

36. Gray L, Sterjovski J, Churchill M, Ellery P, Nasr N, Lewin SR, Crowe SM, Wesselingh S, Cunningham AL, Gorry PR: Uncoupling coreceptor usage of human immunodeficiency virus type I (HIV I) from macrophage tropism reveals biological properties of CCR5-restricted HIV-I isolates from patients with acquired immunodeficiency syndrome. Virology 2005, 337(2):384-398.

37. Kwa D, Vingerhoed J, Boeser B, Schuitemaker H: Increased In Vitro Cytopathicity of CC Chemokine Receptor 5Restricted Human Immunodeficiency Virus Type I Primary Isolates Correlates with a Progressive Clinical Course of Infection. J Infect Dis 2003, I 87(9): | 397-I 403.

38. Scoggins RM, Taylor JR Jr., Patrie J, van't Wout AB, Schuitemaker $H$, Camerini $D$ : Pathogenesis of primary R5 human immunodeficiency virus type I clones in SCID-hu mice. J Virol 2000, 74(7):3205-3216.

39. Berkowitz RD, van't Wout $A B$, Kootstra NA, Moreno ME, LinquistStepps VD, Bare C, Stoddart CA, Schuitemaker H, McCune JM: R5 strains of human immunodeficiency virus type I from rapid progressors lacking X4 strains do not possess X4-type pathogenicity in human thymus. J Virol 1999, 73(9):78|7-7822

40. Kreisberg JF, Kwa D, Schramm B, Trautner V, Connor R, Schuitemaker H, Mullins Jl, van't Wout AB, Goldsmith MA: Cytopathicity of human immunodeficiency virus type I primary isolates depends on coreceptor usage and not patient disease status. J Virol 200 I, 75( I 8):8842-8847.

4I. Repits J, Oberg M, Esbjornsson J, Medstrand P, Karlsson A, Albert J, Fenyo EM, Jansson M: Selection of human immunodeficiency virus type I R5 variants with augmented replicative capacity and reduced sensitivity to entry inhibitors during severe immunodeficiency. J Gen Virol 2005, 86(Pt I0):2859-2869.

42. Karlsson I, Antonsson L, Shi Y, Karlsson A, Albert J, Leitner T, Olde $B$, Owman C, Fenyo EM: HIV biological variability unveiled: frequent isolations and chimeric receptors reveal unprecedented variation of coreceptor use. AIDS 2003, I 7( ( 8):256|-2569.

43. Dunfee RL, Thomas ER, Gorry PR, Wang J, Taylor J, Kunstman K, Wolinsky SM, Gabuzda D: The HIV Env variant N283 enhances macrophage tropism and is associated with brain infection and dementia. Proc Natl Acad Sci USA 2006, 103(4I):15160-15165.

44. Gorry PR, Bristol G, Zack JA, Ritola K, Swanstrom R, Birch CJ, Bell JE, Bannert N, Crawford K, Wang H, Schols D, De Clercq E, Kunstman K, Wolinsky SM, Gabuzda D: Macrophage Tropism of Human Immunodeficiency Virus Type I Isolates from Brain and Lymphoid Tissues Predicts Neurotropism Independent of Coreceptor Specificity. J Virol 200I, 75(2I): 10073-I0089.

45. Gorry PR, Taylor J, Holm GH, Mehle A, Morgan T, Cayabyab M, Farzan M, Wang $\mathrm{H}$, Bell JE, Kunstman K, Moore JP, Wolinsky SM, Gabuzda D: Increased CCR5 affinity and reduced CCR5/CD4 dependence of a neurovirulent primary human immunodeficiency virus type I isolate. J Virol 2002, 76( I 2):6277-6292.

46. Peters PJ, Bhattacharya J, Hibbitts S, Dittmar MT, Simmons G, Bell J, Simmonds P, Clapham PR: Biological analysis of human immunodeficiency virus type I R5 envelopes amplified from brain and lymph node tissues of AIDS patients with neuropathology reveals two distinct tropism phenotypes and identifies envelopes in the brain that confer an enhanced tropism and fusigenicity for macrophages. J Virol 2004, 78(13):6915-6926.

47. Chohan B, Lang D, Sagar M, Korber B, Lavreys L, Richardson B, Overbaugh J: Selection for human immunodeficiency virus type I envelope glycosylation variants with shorter VI-V2 loop sequences occurs during transmission of certain genetic subtypes and may impact viral RNA levels. J Virol 2005, 79( (10):6528-6531

48. Hu QX, Barry AP, Wang ZX, Connolly SM, Peiper SC, Greenberg ML: Evolution of the human immunodeficiency virus type I envelope during infection reveals molecular corollaries of specif- icity for coreceptor utilization and AIDS pathogenesis. I Virol 2000, 74(24): I I858-I I872

49. Jansson M, Backstrom E, Scarlatti G, Bjorndal A, Matsuda S, Rossi P Albert J, Wigzell H: Length variation of glycoprotein 120 V2 region in relation to biological phenotypes and coreceptor usage of primary HIV type I isolates. AIDS Res Hum Retroviruses 200I, I7(I5): |405-|4|4.

50. McCaffrey RA, Saunders C, Hensel M, Stamatatos L: N-linked glycosylation of the V3 loop and the immunologically silent face of gp 120 protects human immunodeficiency virus type I SF 162 from neutralization by anti-gp I 20 and anti-gp4I antibodies. IVirol 2004, 78(7):3279-3295.

5I. Milich L, Margolin BH, Swanstrom R: Patterns of amino acid variability in NSI-like and SI-like V3 sequences and a linked change in the CD4-binding domain of the HIV-I Env protein. Virology 1997, 239(I): 108-118

52. Nabatov AA, Pollakis G, Linnemann T, Kliphius A, Chalaby MI, Paxton WA: Intrapatient alterations in the human immunodeficiency virus type I gp I 20 VIV2 and V3 regions differentially modulate coreceptor usage, virus inhibition by $\mathrm{CC} / \mathrm{CXC}$ chemokines, soluble CD4, and the b 12 and 2 G I 2 monoclonal antibodies. J Virol 2004, 78(I):524-530.

53. Sagar $M, W u X$, Lee $S$, Overbaugh J: Human immunodeficiency virus type I VI-V2 envelope loop sequences expand and add glycosylation sites over the course of infection, and these modifications affect antibody neutralization sensitivity. J Virol 2006, 80(1 9):9586-9598.

54. Shieh JT, Martin J, Baltuch G, Malim MH, Gonzalez-Scarano F: Determinants of syncytium formation in microglia by human immunodeficiency virus type I: role of the VI/V2 domains. J Virol 2000, 74(2):693-70I.

55. Teeraputon S, Louisirirojchanakul S, Auewarakul P: N-linked glycosylation in $\mathrm{C} 2$ region of HIV-I envelope reduces sensitivity to neutralizing antibodies. Viral Immunol 2005, 18(2):343-353.

56. Gray L, Churchill MJ, Keane N, Sterjovski J, Ellett AM, Purcell DFJ, Poumbourios P, Kol C, Wang B, Saksena N, Wesselingh SL, Price P, French M, Gabuzda D, Gorry PR: Genetic and functional analysis of R5X4 human immunodeficiency virus type I envelope glycoprotiens derived from two individuals homozygous for the CCR5delta32 allele. J Virol 2006, 80(7):3684-369I.

57. Ohagen A, Devitt A, Kunstman KJ, Gorry PR, Rose PP, Korber B, Taylor J, Levy R, Murphy RL, Wolinsky SM, Gabuzda D: Genetic and functional analysis of full-length human immunodeficiency virus type I env genes derived from brain and blood of patients with AIDS. I Virol 2003, 77(22): 12336-12345.

58. Binley JM, Wrin T, Korber B, Zwick MB, Wang M, Chappey C, Stiegler G, Kunert R, Zolla-Pazner S, Katinger H, Petropoulos C), Burton DR: Comprehensive cross-clade neutralization analysis of a panel of anti-human immunodeficiency virus type I monoclonal antibodies. J Virol 2004, 78(23): | $3232-13252$.

59. Brown BK, Darden JM, Tovanabutra S, Oblander T, Frost J, SandersBuell E, de Souza MS, Birx DL, McCutchan FE, Polonis VR: Biologic and genetic characterization of a panel of 60 human immunodeficiency virus type $I$ isolates, representing clades A, B, C, D, CRFOI_AE, and CRF02_AG, for the development and assessment of candidate vaccines. J Virol 2005, 79(10):6089-6101.

60. Bures R, Gaitan A, Zhu T, Graziosi C, McGrath KM, Tartaglia J, Caudrelier P, El Habib R, Klein M, Lazzarin A, Stablein DM, Deers M, Corey L, Greenberg ML, Schwartz DH, Montefiori DC: Immunization with recombinant canarypox vectors expressing membrane-anchored glycoprotein 120 followed by glycoprotein 160 boosting fails to generate antibodies that neutralize R5 primary isolates of human immunodeficiency virus type $I$. AIDS Res Hum Retroviruses 2000, I6( I 8):2019-2035.

61. Hierholzer J, Montano S, Hoelscher M, Negrete M, Hierholzer M, Avila MM, Carrillo MG, Russi JC, Vinoles J Alava A Acosta ME, Gianella A, Andrade R, Sanchez JL, Carrion G, Sanchez JL, Russell K, Robb M, Birx D, McCutchan F, Carr JK: Molecular Epidemiology of HIV Type I in Ecuador, Peru, Bolivia, Uruguay, and Argentina. AIDS Res Hum Retroviruses 2002, 18(18): I339-1350.

62. Li M, Gao F, Mascola JR, Stamatatos L, Polonis VR, Koutsoukos M, Voss G, Goepfert P, Gilbert P, Greene KM, Bilska M, Kothe DL, Salazar-Gonzalez JF, Wei X, Decker JM, Hahn BH, Montefiori DC: Human immunodeficiency virus type I env clones from acute and early subtype $B$ infections for standardized assess- 
ments of vaccine-elicited neutralizing antibodies. J Virol 2005, 79(16): $10108-10125$.

63. Spudich SS, Huang W, Nilsson AC, Petropoulos CJ, Liegler TJ, Whitcomb JM, Price RW: HIV-I chemokine coreceptor utilization in paired cerebrospinal fluid and plasma samples: a survey of subjects with viremia. J Infect Dis 2005, I I (6):890-898.

64. Liu SL, Schacker T, Musey L, Shriner D, McElrath MJ, Corey L, Mullins JI: Divergent patterns of progression to AIDS after infection from the same source: human immunodeficiency virus type I evolution and antiviral responses. J Virol 1997, $71(6): 4284-4295$.

65. Kupfer B, Sing T, Schuffler P, Hall R, Kurz R, McKeown A, Schneweis $\mathrm{KE}$, Eberl W, Oldenburg J, Brackmann HH, Rockstroh JK, Spengler U, Daumer MP, Kaiser R, Lengauer T, Matz B: Fifteen years of env C2V3C3 evolution in six individuals infected clonally with human immunodeficiency virus type I. J Med Virol 2007. 79(II): 1629-1639.

66. Chen B, Vogan EM, Gong H, Skehel JJ, Wiley DC, Harrison SC: Structure of an unliganded simian immunodeficiency virus gp I 20 core. Nature 2005, 433(7028):834-84I.

67. Zhou T, Xu L, Dey B, Hessell AJ, Van Ryk D, Xiang SH, Yang X, Zhang MY, Zwick MB, Arthos J, Burton DR, Dimitrov DS, Sodroski J, Wyatt R, Nabel G], Kwong PD: Structural definition of a conserved neutralization epitope on HIV-I gp/20. Nature 2007, 445(7 I 29): $732-737$.

68. Olivieri K, Scoggins RM, Bor YC, Matthews A, Mark D, Taylor JR Jr., Chernauskas D, Hammarskjold ML, Rekosh D, Camerini D: The envelope gene is a cytopathic determinant of CCR5 tropic HIV-I. Virology 2007, 358(I):23-38

69. Price RW: Neurological complications of HIV infection. Lancet 1996, 348(9025):445-452.

70. Shieh JT, Albright AV, Sharron M, Gartner S, Strizki J, Doms RW, Gonzalez-Scarano F: Chemokine receptor utilization by human immunodeficiency virus type $I$ isolates that replicate in microglia. J Virol 1998, 72(5):4243-4249.

7I. Thomas ER, Dunfee RL, Stanton J, Bogdan D, Taylor J, Kunstman K Bell JE, Wolinsky SM, Gabuzda D: Macrophage entry mediated by HIV Envs from brain and lymphoid tissues is determined by the capacity to use low CD4 levels and overall efficiency of fusion. Virology 2007, 360(I):105-II9.

72. Dunfee RL, Thomas ER, Wang J, Kunstman K, Wolinsky SM, Gabuzda $\mathrm{D}$ : Loss of the $\mathbf{N}$-linked glycosylation site at position $\mathbf{3 8 6}$ in the HIV envelope V4 region enhances macrophage tropism and is associated with dementia. Virology 2007, 367(I):222-234

73. Peters PJ, Sullivan WM, Duenas-Decamp MJ, Bhattacharya J, Ankghuambom C, Brown R, Luzuriaga K, Bell J, Simmonds P, Ball J, Clapham PR: Non-macrophage-tropic human immunodeficiency virus type I R5 envelopes predominate in blood, lymph nodes, and semen: implications for transmission and pathogenesis. J Virol 2006, 80(I3):6324-6332.

74. Dey B, Pancera M, Svehla K, Shu Y, Xiang SH, Vainshtein J, Li Y, Sodroski J, Kwong PD, Mascola JR, Wyatt R: Characterization of human immunodeficiency virus type I monomeric and trimeric gp 120 glycoproteins stabilized in the CD4-bound state: antigenicity, biophysics, and immunogenicity. J Virol 2007, 8 I (II):5579-5593.

75. Chang MI, Panorchan P, Dobrowsky TM, Tseng Y, Wirtz D: Singlemolecule analysis of human immunodeficiency virus type gp/20-receptor interactions in living cells. J Virol 2005 79(23): I4748-14755.

76. Steffens CM, Hope T]: Mobility of the human immunodeficiency virus (HIV) receptor CD4 and coreceptor CCR5 in living cells: implications for HIV fusion and entry events. J Virol 2004, 78(I 7):9573-9578.

77. Choe H, Farzan M, Sun Y, Sullivan N, Rollins B, Ponath PD, Wu L, Mackay CR, LaRosa G, Newman W, Gerard N, Gerard C, Sodroski J: The beta-chemokine receptors CCR3 and CCR5 facilitate infection by primary HIV-I isolates. Cell 1996, 85(7): I| $35-1 \mid 48$.

78. Xiang SH, Farzan M, Si Z, Madani N, Wang L, Rosenberg E, Robinson J, Sodroski J: Functional mimicry of a human immunodeficiency virus type I coreceptor by a neutralizing monoclonal antibody. J Virol 2005, 79( I 0):6068-6077.

79. Yang X, Tomov V, Kurteva S, Wang L, Ren X, Gorny MK, ZollaPazner S, Sodroski ]: Characterization of the outer domain of the gp I 20 glycoprotein from human immunodeficiency virus type I. J Virol 2004, 78(23): |2975-I2986.

80. Deng HK, Unutmaz D, KewalRamani VN, Littman DR: Expression cloning of new receptors used by simian and human immunodeficiency viruses. Nature 1997, 388(6639):296-300.

8I. Morgenstern JP, Land H: Advanced mammalian gene transfer: high titre retroviral vectors with multiple drug selection markers and a complementary helper-free packaging cell line. Nucleic Acids Res 1990, I 8( I 2):3587-3596.

82. Platt EJ, Wehrly K, Kuhmann SE, Chesebro B, Kabat D: Effects of CCR5 and CD4 cell surface concentrations on infections by macrophagetropic isolates of human immunodeficiency virus type 1. J Virol 1998, 72(4):2855-2864.

83. Gao F, Morrison SG, Robertson DL, Thornton CL, Craig S, Karlsson G, Sodroski J, Morgado M, Galvao-Castro B, von Briesen H, et al: Molecular cloning and analysis of functional envelope genes from human immunodeficiency virus type I sequence subtypes A through G. The WHO and NIAID Networks for HIV Isolation and Characterization. J Virol 1996, 70(3): 165 I-I 667.

84. He J, Chen Y, Farzan M, Choe H, Ohagen A, Gartner S, Busciglio J, Yang X, Hofmann W, Newman W, Mackay CR, Sodroski J, Gabuzda D: CCR3 and CCR5 are co-receptors for HIV-I infection of microglia. Nature 1997, 385(66 I7):645-649.

85. Gorry PR, Dunfee RL, Mefford ME, Kunstman K, Morgan T, Moore JP, Mascola JR, Agopian K, Holm GH, Mehle A, Taylor J, Farzan M, Wang H, Ellery P, Willey SJ, Clapham PR, Wolinsky SM, Crowe SM, Gabuzda $D$ : Changes in the V3 region of gp I 20 contribute to unusually broad coreceptor usage of an HIV-I isolate from a CCR5 Delta32 heterozygote. Virology 2007, 362(I):163-178.

86. Gorry PR, Howard JL, Churchill MJ, Anderson JL, Cunningham A, Adrian D, McPhee DA, Purcell DF: Diminished production of human immunodeficiency virus type $I$ in astrocytes results from inefficient translation of gag, env, and nef mRNAs despite efficient expression of Tat and Rev. J Virol 1999, 73(I):352-36I.

87. Yang X, Kurteva S, Lee S, Sodroski J: Stoichiometry of antibody neutralization of human immunodeficiency virus type $I$. J Virol 2005, 79(6):3500-3508

88. Yang X, Wyatt R, Sodroski J: Improved elicitation of neutralizing antibodies against primary human immunodeficiency viruses by soluble stabilized envelope glycoprotein trimers. J Virol 200I, 75(3): I |65-II7I.

89. Burton DR, Barbas CF 3rd, Persson MA, Koenig S, Chanock RM, Lerner RA: A large array of human monoclonal antibodies to type I human immunodeficiency virus from combinatorial libraries of asymptomatic seropositive individuals. Proc Natl Acad Sci USA I991, 88(22): I0I34-10137.

90. Burton DR, Pyati J, Koduri R, Sharp SJ, Thornton GB, Parren PW, Sawyer LS, Hendry RM, Dunlop N, Nara PL, et al.: Efficient neutralization of primary isolates of HIV-I by a recombinant human monoclonal antibody. Science 1994, 266(5 I 87): 1024-I027.

9I. Muster T, Guinea R, Trkola A, Purtscher M, Klima A, Steindl F, Palese $P$, Katinger $H$ : Cross-neutralizing activity against divergent human immunodeficiency virus type $I$ isolates induced by the gp4 I sequence ELDKWAS. J Virol 1994, 68(6):403 I-4034.

92. Trkola A, Pomales AB, Yuan $\mathrm{H}$, Korber B, Maddon PJ, Allaway GP, Katinger H, Barbas CF 3rd, Burton DR, Ho DD, et al.: Cross-clade neutralization of primary isolates of human immunodeficiency virus type I by human monoclonal antibodies and tetrameric CD4-IgG. J Virol 1995, 69(II):6609-66I7.

93. Trkola A, Purtscher M, Muster T, Ballaun C, Buchacher A, Sullivan N, Srinivasan K, Sodroski J, Moore JP, Katinger H: Human monoclonal antibody 2 G 12 defines a distinctive neutralization epitope on the gp 120 glycoprotein of human immunodeficiency virus type I. J Virol 1996, 70(2): I 100-I I08.

94. Chen B, Vogan EM, Gong H, Skehel JJ, Wiley DC, Harrison SC: Determining the structure of an unliganded and fully glycosylated SIV gpI20 envelope glycoprotein. Structure 2005, I3(2): |97-2।I.

95. Huang CC, Tang M, Zhang MY, Majeed S, Montabana E, Stanfield RL Dimitrov DS, Korber B, Sodroski J, Wilson IA, Wyatt R, Kwong PD: Structure of a V3-containing HIV-I gp I 20 core. Science 2005, 3 I0(5750): 1025-1028.

96. Sobolev V, Sorokine A, Prilusky J, Abola EE, Edelman M: Automated analysis of interatomic contacts in proteins. Bioinformatics 1999, I5(4):327-332. 